\title{
Isoliquiritigenin alleviates early brain injury after experimental intracerebral hemorrhage via suppressing ROS- and/or NF-kB-mediated NLRP3 inflammasome activation by promoting Nrf2 antioxidant pathway
}

Jun Zeng ${ }^{1}$, Yizhao Chen ${ }^{1 *}$ (D), Rui Ding ${ }^{2}$, Liang Feng ${ }^{3}$, Zhenghao Fu ${ }^{4}$, Shuo Yang ${ }^{5}$, Xinqing Deng ${ }^{6}$, Zhichong Xie ${ }^{1}$ and Shizhong Zheng ${ }^{1}$

\begin{abstract}
Background: Intracerebral hemorrhage $(\mathrm{ICH})$ induces potently oxidative stress responses and inflammatory processes. Isoliquiritigenin (ILG) is a flavonoid with a chalcone structure and can activate nuclear factor erythroid-2 related factor 2 (Nrf2)-mediated antioxidant system, negatively regulate nuclear factor-KB (NF-KB) and nod-like receptor family, pyrin domain-containing 3 (NLRP3) inflammasome pathways, but its role and potential molecular mechanisms in the pathology following ICH remain unclear. The present study aimed to explore the effects of ILG after ICH and underlying mechanisms.

Methods: ICH model was induced by collagenase IV (0.2 U in $1 \mu \mathrm{l}$ sterile normal saline) in male Sprague-Dawley rats weighing $280-320 \mathrm{~g}$. Different doses of ILG (10, 20, or $40 \mathrm{mg} / \mathrm{kg})$ was administrated intraperitoneally at $30 \mathrm{~min}$, $12 \mathrm{~h}, 24 \mathrm{~h}$, and $48 \mathrm{~h}$ after modeling, respectively. Rats were intracerebroventricularly administrated with control scramble small interfering RNA (siRNA) or Nrf2 siRNA at $24 \mathrm{~h}$ before $\mathrm{ICH}$ induction, and after $24 \mathrm{~h}$, ICH model was established with or without ILG (20 mg/kg) treatment. All rats were dedicated at 24 or $72 \mathrm{~h}$ after ICH. Neurological deficits, histological damages, brain water content (BWC), blood-brain barrier (BBB) disruption, and neuronal degeneration were evaluated; quantitative real-time RT-PCR (qRT-PCR), immunohistochemistry/immunofluorescence, western blot, and enzyme-linked immunosorbent assay (ELISA) were carried out; catalase, superoxide dismutase activities and reactive oxygen species (ROS), and glutathione/oxidized glutathione contents were measured.

(Continued on next page)
\end{abstract}

\footnotetext{
* Correspondence: yizhao_chen@hotmail.com

${ }^{1}$ Department of Neurosurgery, Zhujiang Hospital, The National Key Clinical Specialty, The Neurosurgery Institute of Guangdong Province, Guangdong Provincial Key Laboratory on Brain Function Repair and Regeneration, The Engineering Technology Research Center of Education Ministry of China, Southern Medical University, Guangzhou 510282, China

Full list of author information is available at the end of the article
} 
(Continued from previous page)

Results: ILG (20 and 40 mg/kg) markedly alleviated neurological deficits, histological damages, BBB disruption, brain edema, and neuronal degeneration, but there was no significant difference between two dosages. ILG (20 mg/kg) significantly suppressed the NF-KB and NLRP3 inflammasome pathways and activated Nrf2-mediated antioxidant system. Gene silencing of Nrf2 aggravated the neurological deficits, brain edema, and neuronal degeneration and increased the protein levels of NF-KB p65, NLRP3 inflammasome components, and IL-1 $\beta$. ILG delivery significantly attenuated the effects of Nrf2 siRNA interference mentioned above.

Conclusions: Intraperitoneal administration of ILG after ICH reduced early brain impairments and neurological deficits, and the mechanisms were involved in the regulation of ROS and/or NF-KB on the activation of NLRP3 inflammasome pathway by the triggering of Nrf2 activity and Nrf2-induced antioxidant system. In addition, our experimental results may make ILG a potential candidate for a novel therapeutical strategy for ICH.

Keywords: ICH, Early brain injury, ILG, Nrf2, ROS, NF-KB, NLRP3 inflammasome

\section{Background}

Spontaneous intracerebral hemorrhage (ICH) belongs to a fatal cerebrovascular disorder, accounting for 15 to $20 \%$ in all stroke types, commonly accompanied with high morbidity and mortality $[1,2]$. Brain injury after $\mathrm{ICH}$ is broadly classified as primary brain injury and secondary brain injury $[3,4]$. Primary brain injury occurring within first several hours post ICH is caused by the hemorrhage and growth of hematoma which lead to the mechanical impairments and compression of adjacent cerebrovascular architecture [1,3-5]. Hematoma size is a powerful and easy-to-use predictor of 30-day mortality and morbidity in patients with $\mathrm{ICH}$, and large hemorrhage often indicates a poor prognosis $[4,6]$. Blood components extravasated from the ruptured blood vessels and degradation products of blood cells can induce severe secondary brain injury including neurobehavioral deterioration, brain cell death, cerebral edema, and blood-brain barrier (BBB) disruption $[1,3-5]$. Though the understanding of pathophysiological mechanisms to brain injury after ICH has been well improved in recent decades, there are still no effective therapies being available for the prevention of $\mathrm{ICH}$-induced brain impairments $[3-5,7]$. Furthermore, increasing evidences have shown that inflammatory response and oxidative stress which occur following $\mathrm{ICH}$ play a key role in pathophysiological processes of $\mathrm{ICH}$-induced early brain dysfunctions $[3-5,7,8]$.

Nuclear factor erythroid-2 related factor 2 (Nrf2) is a key transcription factor and master regulator of the cellular response of oxidative stress, which can induce the expression of antioxidant and detoxification enzymes and downstream proteins such as $\mathrm{NAD}(\mathrm{P}) \mathrm{H}$ : quinone oxidoreductase-1 (NQO1), catalase (CAT), superoxide dismutase (SOD), heme oxygenase-1 (HO-1), glutathione peroxidase (GPX), and glutathione-S-transferase (GST) $[9,10]$. Recent study report showed that the expression of Nrf2 was gradually increased following $\mathrm{ICH}$ at $2 \mathrm{~h}$, peaked at $24 \mathrm{~h}$, and then slightly decreased with time until 10 days [11]. In addition, Nrf2 has been identified to hold the neuroprotective effects against the early brain injury after $\mathrm{ICH}$ by translocating into nucleus after being activated, binding to the antioxidant response element (ARE), then initiating the expression of a series of antioxidant and detoxification enzymes and proteins, as a result, improving neurological deficits, alleviating brain edema, and decreasing the infiltration of inflammatory cells [11-15].

The NLRP3 (NALP3, cryopyrin) inflammasome [NLR (Nod-like receptor) family, pyrin domain-containing 3 inflammasome], a best characterized member of NLR family and one of the key components of innate immune system, has been reported by others $[8,16]$ and us [17] to take part in the processes of early brain injury after $\mathrm{ICH}$ via facilitating caspase-1 and interleukin-1beta (IL-1 $\beta$ ) processing, which amplifies the inflammatory response and blockade or knockdown of NLRP3 inflammasome can alleviate the brain damages $[8,16,17]$. Recently, reports have indicated that Nrf2 could negatively regulate NLRP3 inflammasome activity by inhibiting reactive oxygen species (ROS)-induced NLRP3 inflammasome activation $[18,19]$. However, the relationship between Nrf2 antioxidant pathway and NLRP3 inflammasome activation and whether Nrf2 reduces the early brain injury via the suppression of NLRP3 inflammasome and whether the above-mentioned inhibitory effect is involved in Nrf2 mediated ROS and/or nuclear factor- $\mathrm{kB}$ (NF- $\mathrm{kB}$ ) suppression have not been explored in the experimental rat ICH model.

Isoliquiritigenin (ILG), a component of Glycyrrhiza uralensis (G. uralensis), is a flavonoid with a chalcone structure and it holds multiple biological activities [20]. Recent papers have shown that ILG was a potent inhibitor of NLRP3 inflammasome [21, 22] and NF-kB [23-25], thus exerting a protective effect. Also, there were reports showing that ILG could activate Nrf2mediated antioxidant pathway via promoting Nrf2 translocation into the nucleus and then initiating a series of genes to express [9, 26-29]. However, it remains unclear 
whether ILG has a protective effect against the early brain injury following $\mathrm{ICH}$, and the detailed molecular mechanisms have not been elucidated. Thus, in this study, we are attempting to explore the effects of ILG on the early brain injury after an experimental rat intracerebral hemorrhage model and the potential molecular mechanisms.

\section{Methods}

\section{Animals}

Adult male Sprague-Dawley rats (SD rats) weighing between 280 and $320 \mathrm{~g}$ (8-10 weeks) were obtained from the Animal Experiment Center of Southern Medical University. All experimental procedures and animal care were approved by the Southern Medical University Ethics Committee and were conducted in accordance with the guidelines of the National Institutes of Health on the care and use of animals. All rats were housed in a light-, temperature-, and humidity-controlled specific pathogenfree (SPF) environment (under a 12-h light/dark cycle with constant temperature about $25{ }^{\circ} \mathrm{C}$ and relative humidity approximating 55\%). All rats had free access to standard food and water during the experiments.

\section{Experimental design and groups}

Experiments were conducted in a rat model of collagenase type IV-induced ICH. In the first experiment, 180 rats were used (183 rats suffered to the surgery, 180 rats survived) to evaluate the effects of ILG on the early brain injury post $\mathrm{ICH}$. The rats were randomly and evenly assigned to five groups of 36 rats each, namely, sham group, ICH + vehicle-1 [dimethylsulfoxide (DMSO)] group, ICH + ILG $10 \mathrm{mg} / \mathrm{kg}$ group, ICH + ILG $20 \mathrm{mg} / \mathrm{kg}$ group, and ICH + ILG $40 \mathrm{mg} / \mathrm{kg}$ group. All rats in this experiment were evaluated with a Modified Neurological Severity Score (mNSS) $(n=12)$ scale at 24 or $72 \mathrm{~h}$ after $\mathrm{ICH}$, except for the rats that perform extravasation detection of Evans blue (EB) dyes $(n=6)$ at the same time points. Then, the rats were killed, and brain tissue samples were taken to perform brain water content (BWC) measurements $(n=6)$, hematoxylin and eosin (H\&E) staining $(n=6)$, and Fluoro-Jade ${ }^{\bullet} \mathrm{C}$ (FJC) staining $(n=6)$.

In the second experiment, 120 rats were used (122 rats experienced the operation, 120 rats survived) to explore the underlying molecular mechanisms of ILG's effects on the early brain injury after $\mathrm{ICH}$. The rats were randomized into four groups (30 rats per group): sham group, $\mathrm{ICH}$ group, ICH + vehicle-1 (DMSO) group, and ICH + ILG $20 \mathrm{mg} / \mathrm{kg}$ group. All rats in the experiment were sacrificed at $24 \mathrm{~h}$ after $\mathrm{ICH}$ for real-time reverse transcriptionquantitative polymerase chain reaction (RT-qPCR) $(n=6)$, western blot (WB) $(n=6)$, immunohistochemistry (IHC)/ immunofluorescence (IF) $(n=6)$, enzyme-linked immunosorbent assay (ELISA) $(n=6)$, and glutathione/oxidized glutathione (GSH/GSSG) contents, ROS content, CAT activity, and SOD activity analyses $(n=6)$.

In the third experiment, 132 rats were used (132 of 137 rats after the surgery survived) to execute the study on effects of Nrf2 small interfering RNA (siRNA) interference and Nrf2 siRNA together with ILG co-administration on early brain injury following ICH. The rats were randomly divided into six groups (sham group, $\mathrm{ICH}+$ vehicle-2 [mixtures of Entranster ${ }^{\mathrm{TM}}$ in vivo transfection reagent and siRNA diluent (RNase-free $\mathrm{H}_{2} \mathrm{O}$ )] group, $\mathrm{ICH}+$ control scramble siRNA group, ICH + Nrf2 siRNA group, ICH + Nrf2 siRNA + vehicle-1 group, ICH + Nrf2 siRNA + ILG $20 \mathrm{mg} / \mathrm{kg}$ group). All rats were decapitated to perform related RT-qPCR $(n=6), \mathrm{WB}(n=6)$, mNSS scoring $(n=6)$, $\mathrm{BWC}(n=6)$, FJC staining analyses $(n=6)$.

\section{ICH model}

The procedure for $\mathrm{ICH}$ model in rats has been described in previous publications with some small modifications $[17,30]$. In brief, the rats were anesthetized by intraperitoneal injection (i.p.) of pentobarbital sodium $(45 \mathrm{mg} /$ $\mathrm{kg})$. Then, the animals were placed in a rat brain stereotaxic apparatus and under aseptic condition. Rectal temperature was maintained at $37{ }^{\circ} \mathrm{C}$ throughout the surgical procedure using an insulation board connected with water bath circulation system. Next, a midline incision on the scalp to expose the skull and bregma and a cranial burr hole ( $1 \mathrm{~mm}$ in diameter) was drilled in the right part of the brain, a $5-\mu l$ microsyringe with a needle tip (Shanghai high pigeon industry \& trade co., LTD, Shanghai, China) was inserted stereotactically through the burr hole and into the right striatum which coordinates were $0.1 \mathrm{~mm}$ anterior, $3.5 \mathrm{~mm}$ lateral, and $6.0 \mathrm{~mm}$ ventral to the bregma. Collagenase type IV $(0.2 \mathrm{U}$ in $1 \mu \mathrm{l}$ sterile normal saline) was administrated over a period of $10 \mathrm{~min}$ via stereotaxic intrastriatal injection. The needle was kept in situ for an additional $10 \mathrm{~min}$ to prevent back-flow. Then, the microsyringe was slowly removed and the craniotomy was sealed with bone wax. Finally, the wound was sutured. The sham-operated rats were treated via the same way except that they were administrated $1 \mu \mathrm{l}$ sterile normal saline into the right striatum. The rats were allowed to recover in separate cages with free access to food and water.

\section{In vivo siRNA transfection and drug delivery}

The transfection of Nrf2 siRNA for rat brains in vivo were conducted according to the method described formerly $[17,31,32]$. Briefly, the rats were placed under anesthesia, then a cranial burr hole (1 $\mathrm{mm}$ in diameter) was drilled, following a $25-\mu \mathrm{l}$ microsyringe with a needle tip (Shanghai high pigeon industry \& trade co., LTD, Shanghai, China) was inserted stereotaxically into the right lateral ventricle. The stereotaxic coordinates 
were $1.5 \mathrm{~mm}$ posterior, $1.0 \mathrm{~mm}$ lateral, and $3.2 \mathrm{~mm}$ below the horizontal plane of the bregma [32]. Nrf2 siRNA (sc-156128, Santa Cruz biotechnology, USA) and control scramble siRNA (sc-37007, Santa Cruz Biotechnology, USA) were applied with in vivo transfection reagent (Entranster ${ }^{\mathrm{TM}}$-in vivo, 18668-11-1, Engreen Biosystem Co, Ltd., Beijing, China) at $24 \mathrm{~h}$ before modeling by intracerebroventricular injection [31, 32]. The microsyringe was left in place for an additional $10 \mathrm{~min}$ after administration and then slowly withdrawn. At last, the incision was closed with sutures. The sham-operated rats received a cranial burr hole, but only a needle was inserted.

ILG (1811912, Shanghai Macklin Biochemical Co., Ltd., Shanghai, China) was dissolved into DMSO (D5879, Sigma-Aldrich) solution $(20 \mathrm{mg} / \mathrm{ml})$. The rats were administrated intraperitoneally with either ILG at 10, 20, and $40 \mathrm{mg} / \mathrm{kg}$ or the same volume of DMSO at $30 \mathrm{~min}$, $12 \mathrm{~h}, 24 \mathrm{~h}$, and $48 \mathrm{~h}$ after $\mathrm{ICH}$ induction.

\section{Behavioral assessment}

We used a mNSS scale [33, 34] to assess the behavioral deficits at $24 \mathrm{~h}$ and $72 \mathrm{~h}$ after ICH, which was performed by two trained investigators and both of whom had been blinded to animal grouping. The mNSS is consisted of motor, sensory, balance, and reflex tests. Neurological function is graded via the scale of $0-18$ points $(1-6$, mild injury; 7-12, moderate injury; $13-18$, severe injury; the scores of 0 and 18 represent normal performance and severe neurological deficit, respectively). In the severity scores of neurological function injury, 1 score point is obtained for the incapacity to complete the test or the absence of a tested reflex. Thus, a higher score indicates a more severe neurological injury [33-35].

\section{Measurement of BWC}

BWC was evaluated via a wet/dry weight method, as previously described [36, 37]. Briefly, at 24 or $72 \mathrm{~h}$ after $\mathrm{ICH}$, the rats were deeply anesthetized with an i.p. of pentobarbital sodium and then were decapitated. The brain of the rats were immediately removed and separated into five parts, namely ipsilateral and contralateral cortex, ipsilateral and contralateral basal ganglia, and cerebellum. The cerebellum was used as an internal control. Each part was placed on a pre-weighed piece of aluminum foil and obtained the wet weight by an electric analytic balance, and then was dried at $100{ }^{\circ} \mathrm{C}$ for $24 \mathrm{~h}$ in an electric oven to get the dry weight. BWC was assessed using the following formula: [(wet weight - dry weight) $] /($ wet weight $) \times 100 \%$.

\section{Evaluation of BBB permeability}

Quantitative analysis of BBB permeability was evaluated via EB dye (Wako Pure Chemical Industries, Ltd., Japan) extravasation, as described previously with minor modifications [38-40]. Briefly, the rats were anesthetized and administrated intravenously $2 \%$ EB solution in normal saline $(4 \mathrm{ml} / \mathrm{kg})$ by the femoral vein. After a circulation of $2 \mathrm{~h}$, intracardiac perfusion was performed under deep anesthesia with $0.01 \mathrm{M}$ phosphate buffer solution (PBS) (pH 7.4) of $250 \mathrm{ml}$ to clear EB dyes in cerebral circulation. Subsequently, the brains were removed and the brain samples were immediately separated into the left hemisphere and right hemisphere. Tissue samples were then incubated in 50\% trichloroacetic acid solution $(2 \mathrm{ml})$. Following homogenization and centrifugation $(15,000 \mathrm{rpm}$ for $20 \mathrm{~min})$, the supernatant $(1 \mathrm{ml})$ was diluted with ethanol (1:3), and its fluorescence intensity was measured at an excitation wavelength of $620 \mathrm{~nm}$ and an emission wavelength of $680 \mathrm{~nm}$ with an automatic microplate reader. The EB dye leakage was expressed as micrograms per gram brain weight.

\section{Preparation of paraffin-embedded sections}

Paraffin-embedded sections were made as previously described [17, 35, 40] with some modifications. After deep anesthetization with pentobarbital sodium, the rats were transcardially perfused with $250 \mathrm{ml}$ of $0.01 \mathrm{M} \mathrm{PBS}$ (pH 7.4) followed by $500 \mathrm{ml} \mathrm{4 \%}$ paraformaldehyde solution. And then, the brains were removed and post-fixed by immersion in the same fixative solution at $4{ }^{\circ} \mathrm{C}$ for 24-48 h. After dehydration and vitrification, tissue samples were embedded in paraffin, and $4-\mu \mathrm{m}$ sections were prepared. The sections were then dewaxed in xylene, rehydrated in graded ethanol and deionized water, and then processed for H\&E, IHC, IF, and FJC staining.

\section{H\&E staining}

The coronal brain sections (4- $\mu \mathrm{m}$ thickness, paraffinembedded) were prepared as mentioned above, then were stained with eosin for $10 \mathrm{~s}$ followed by hematoxylin re-staining for $5 \mathrm{~min}$. After dehydrated in graded ethanol and cleared in xylene, slides were mounted by neutral balsam. Images were obtained using a microscope (Leica-DM2500, Germany).

\section{IHC staining}

IHC staining was conducted as described previously $[35,36]$ with a few modifications. Coronal paraffinembedded brain sections (4- $\mu \mathrm{m}$ thickness) were prepared as before-mentioned and antigen retrieval was performed by heat treatment in a microwave oven for $21 \mathrm{~min}$ in Tris-ethylene diamine tetraacetic acid (EDTA) buffer solution (0.05 mol/l Tris, $0.001 \mathrm{~mol} / \mathrm{l}$ EDTA; pH 8.5). Endogenous peroxidase activity was inactivated using $0.3 \% \mathrm{H}_{2} \mathrm{O}_{2}$ for $10 \mathrm{~min}$ followed by washing with PBS. After blocking by $5 \%$ bovine serum albumin (BSA) for $20 \mathrm{~min}$, the slides were incubated overnight at $4{ }^{\circ} \mathrm{C}$ with 
the following primary antibodies used: rabbit monoclonal anti-NF-KB p65 (D14E12) XP ${ }^{\circ}$ antibody (1:800, \#8242, Cell Signaling Technology); rabbit polyclonal anti-Nrf2 (L593) antibody (1:200, BS1258, Bioworld); rabbit polyclonal antiHO-1 antibody (1:200, BS6626, Bioworld); goat polyclonal anti-NQO1 antibody (1:200, ab2346, Abcam); mouse monoclonal anti-Cryopyrin (NLRP3) (6F12) antibody (1:100, sc-134306, Santa Cruz Biotechnology); mouse monoclonal anti-3-Nitrotyrosine (3-NT) antibody [39B6] (1:200, ab61392, Abcam); mouse monoclonal anti-8Hydroxyguanosine (8-OHdG) antibody [N45.1] (1:200, ab48508, Abcam); rabbit polyclonal anti-Iba-1 antibody (1:600, WAKO, Osaka, Japan); and mouse monoclonal anti-CD68 antibody [ED1] (1:200, ab31630, Abcam). After washing with PBS, the sections were incubated with biotinylated goat anti-mouse IgG, goat anti-rabbit IgG, and donkey anti-goat IgG secondary antibodies for $20 \mathrm{~min}$ and then incubated with horseradish peroxidase (HRP)-streptavidin reagent for $20 \mathrm{~min}$. Finally, immunoreactivity was detected using 3,3-diaminobenzidine (DAB), followed by re-staining with hematoxylin. Images were obtained by using a microscope (Leica-DM2500, Germany). The number of immunopositive cells in the perihematomal region was counted in a blinded manner and was expressed as number $/ 0.1 \mathrm{~mm}^{2}$ areas.

\section{IF staining}

IF staining was performed as described previously [17, 35] with a few modifications. Coronal paraffin-embedded 4$\mu \mathrm{m}$ thickness brain sections were prepared as mentioned above. Antigen retrieval was conducted as IHC staining. After blocking by $5 \%$ BSA for $40 \mathrm{~min}$, sections were incubated overnight at $4{ }^{\circ} \mathrm{C}$ with the following primary antibody used: rabbit polyclonal anti-myeloperoxidase (MPO) antibody (1:50, ab9535, Abcam). After washing with PBS, sections were then incubated with the secondary antibody: Alexa Fluor 594 goat anti-rabbit IgG (H + L) (1:100, A11012, Invitrogen) for $1 \mathrm{~h}$ at room temperature. Following washing three times with PBS, the sections were re-stained by 4'6-diamidino-2-phenylindole (DAPI) for $10 \mathrm{~min}$. Then, images were obtained with a fluorescence microscope (ZEISS-AXIO Scope. Al, Germany).

\section{FJC staining}

For the detection of degenerating neuron, FJC staining was conducted as described previously with some modifications [41]. Briefly, rat brain sections were prepared as mentioned above, then sections were rinsed with distilled water and immersed into $0.06 \%$ potassium permanganate solution for 10 min followed by transferred into a $0.0001 \%$ solution of FJC (AG325, Merck millipore) dissolved in $0.1 \%$ acetic acid vehicle for $30 \mathrm{~min}$. After washing with distilled water, the slides were put into an oven at $50{ }^{\circ} \mathrm{C}$ for $20 \mathrm{~min}$. The dried slides were then cleared in xylene for $5 \mathrm{~min}$ and then coverslipped with DPX mountant for histology (06522-100 ml, Sigma). Four high-power images ( $\times 400$ magnification) were taken around hematoma using a fluorescence microscope (ZEISS-AXIO Scope, Al, Germany) in each slide. FJC staining positive cells were counted on these four areas.

\section{Real-time RT-qPCR}

Quantitative real-time RT-PCR assessment for the messenger RNA (mRNA) levels was conducted via using Prime Script RT-PCR kits (RR047A and RR820A, Takara) according to the manufacturer's instructions. The mRNA level of $\beta$-actin was used as an internal control. The realtime PCR program steps were $95^{\circ} \mathrm{C}$ for $30 \mathrm{~s}, 40$ cycles of $95{ }^{\circ} \mathrm{C}$ for $3 \mathrm{~s}, 60{ }^{\circ} \mathrm{C}$ for $34 \mathrm{~s}$. The mRNA level of each target gene was normalized to that of $\beta$-actin mRNA. Fold-induction was calculated using the $2^{-\Delta \Delta C T}$ method, as previously described $[42,43]$. The specific sequences of primers used were shown as Table 1.

\section{WB}

WB was performed according to our previous study method $[17,35]$. We used the following primary antibodies to perform the WB analyses: rabbit monoclonal anti-NF-kB p65 (D14E12) XP॰ antibody (1:1000, \#8242, Cell Signaling Technology); rabbit polyclonal anti-Nrf2 (L593) antibody (1:500, BS1258, Bioworld); mouse monoclonal anti-Cryopyrin (NLRP3) (6F12) antibody (1:1000, sc-134306, Santa Cruz Biotechnology); rabbit polyclonal anti-PYCARD (ASC) antibody (1:500, A1170, Abclonal); goat polyclonal anti-caspase-1 p20 (M-19) antibody(1:1000, sc-1218, Santa Cruz Biotechnology); rabbit polyclonal anti-IL-1 $(\mathrm{H}-153)$ antibody (1: 1000, sc7884, Santa Cruz Biotechnology); and rabbit polyclonal anti-IL-18 (H-173) antibody (1:1000, sc-7954, Santa Cruz Biotechnology), and glyceraldehyde 3-phosphate dehydrogenase (GAPDH) (1:1000, Cell Signaling Technology) was used as an internal reference. Blot bands were quantified via densitometry with ImageJ software (National Institutes of Health, Baltimore, MD, USA), and protein levels were expressed as the ratio of values of the detected protein bands to that of GAPDH bands.

\begin{tabular}{|c|c|c|}
\hline Gene & Forward primer $\left(5^{\prime}-3^{\prime}\right)$ & Reverse primer $\left(5^{\prime}-3^{\prime}\right)$ \\
\hline NLRP3 & CGGTGACCTTGTGTGTGCTT & TCATGTCCTGAGCCATGGAAG \\
\hline ASC & GACAGTACCAGGCAGTTCGT & AGTAGGGCTGTGTTTGCCTC \\
\hline Caspase-1 & GAACAAAGAAGGTGGCGCAT & AGACGTGTACGAGTGGGTGT \\
\hline IL-1 beta & CCTATGTCTTGCCCGTGGAG & CACACACTAGCAGGTCGTCA \\
\hline IL-18 & ACCACTTTGGCAGACTTCACT & ACACAGGCGGGTTTCTTTTG \\
\hline Nqo1 & GTTGCCTGGCTTGCTTTCA & ACAGCCGTGGCAGAACTATC \\
\hline $\mathrm{HO}-1$ & GGTGATGGCCTCCTTGTACC & GTGGGGCATAGACTGGGTTC \\
\hline Actin & TCAGCAAGCAGGAGTACGATG & GTGTAAAACGCAGCTCAGTAACA \\
\hline
\end{tabular}




\section{Cytokine ELISA assay}

At $24 \mathrm{~h}$ after $\mathrm{ICH}$, the rats were deeply anesthetized. The serum samples from intracardiac puncture blood and the supernatant samples from perihematomal brain tissue homogenate were obtained and stored at $-80{ }^{\circ} \mathrm{C}$ until use. Measurements of IL-1 $\beta$ and IL-18 levels were conducted by a double-antibody sandwich ELISA Array Kit according to the reagent manufacturer's instructions. Briefly, prepared tissue supernatant or serum samples were added to monoclonal antibody enzyme well which is pre-coated with rats IL- $1 \beta$ or IL-18 antibodies labeled with biotin and combined with Streptavidin-HRP to form immune complex, then incubated for $1.5 \mathrm{~h}$ in a $37{ }^{\circ} \mathrm{C}$ condition and washed three times with PBS to remove the uncombined enzyme. After adding the chromogen solution A and B, the samples were detected using an automatic microplate reader at $450 \mathrm{~nm}$.

\section{Measurements of CAT activity, SOD activity and ROS content, GSH/GSSG contents}

CAT assay kit (visible light) (A007-1), total SOD assay kit (Hydroxylamine method) (A001-1), ROS assay kit (E004), and total GSH/GSSG assay kit (A061-1) were all purchased from Nanjing Jiancheng Bioengineering Institute (Nanjing, China) and were used to measure the CAT activity, SOD activity and ROS content, GSH/ GSSG contents according to the instructions of reagent manufacturers, respectively.

\section{Statistical analysis}

All data were presented as means \pm standard deviation (SD). Statistical analyses were performed with SPSS version 19.0 software (SPSS, Inc., Chicago, IL, USA), and plots were drawn by GraphPad Prism 5 software (GraphPad Software, Inc., San Diego, CA). If data are equal variances, one-way analysis of variance (ANOVA) followed by least significant difference (LSD) tests were used to compare differences among multiple groups; for the results being unequal, Dunnett's T3 tests were taken into account. Differences with a $p<0.05$ were considered statistically significant.

\section{Results}

ILG improved behavioral deficits and reduced histological damages at 24 and $72 \mathrm{~h}$ after ICH by intraperitoneal administration

Figure 1a shows the representative macrographs (left, sham, $24 \mathrm{~h}$; right, $\mathrm{ICH}, 24 \mathrm{~h}$ ). The rats subject to $\mathrm{ICH}$ induction showed obvious behavioral deficits at 24 and $72 \mathrm{~h}$ after ICH graded by a mNSS score scale $(p<0.01$ vs. sham, $24 \mathrm{~h}$ and $72 \mathrm{~h}$ ). Administration of ILG at the dosage of $10 \mathrm{mg} / \mathrm{kg}$ was not significantly effective for the improvement of behavioral deficits (vehicle-DMSO vs. $10 \mathrm{mg} / \mathrm{kg}: 10.33 \pm 1.07$ vs. $10.25 \pm 1.14, p>0.05,24 \mathrm{~h}$;
$8.92 \pm 0.79$ vs. $9.00 \pm 0.95, p>0.05,72$ h). However, ILG obviously reduced the mNSS scores at $20 \mathrm{mg} / \mathrm{kg}$ (vehicle-DMSO vs. $20 \mathrm{mg} / \mathrm{kg}$ : vs. $8.25 \pm 0.87, p<0.01$, $24 \mathrm{~h}$; vs. $6.25 \pm 1.06, p<0.01,72 \mathrm{~h})$ and $40 \mathrm{mg} / \mathrm{kg}$ (vehicle-DMSO vs. $40 \mathrm{mg} / \mathrm{kg}$ : vs. $8.17 \pm 0.94, p<0.01$, $24 \mathrm{~h}$; vs. $6.83 \pm 1.03, p<0.01,72 \mathrm{~h}$ ), but the effects between two dosages were no significant difference (20 vs. $40 \mathrm{mg} / \mathrm{kg}, p>0.05,24$ and $72 \mathrm{~h}$ ) (Fig. 1b). Consistent with the behavioral results, H\&E staining of brain tissues surrounding the hematoma showed that ILG treatment obviously improved histological impairments at the dosages of 20 and $40 \mathrm{mg} / \mathrm{kg}$, but $10 \mathrm{mg} / \mathrm{kg}$ were not (Fig. 1c). Besides, we also evaluated the effect of ILG $(20 \mathrm{mg} / \mathrm{kg})$ on hematoma volume at 24 and $72 \mathrm{~h}$ after $\mathrm{ICH}$ induction (Additional file 1D). Typical magnetic resonance imaging (MRI) T2-weighted images (T2WI) were obtained (Additional file 2A). The hematoma volume of ICH + DMSO group at 24 and $72 \mathrm{~h}$ after $\mathrm{ICH}$ were $24.81 \pm 1.64,29.11 \pm 2.06 \mathrm{~mm}^{3}$, respectively. ILG administration significantly reduced hematoma volume to $22.95 \pm 3.26 \mathrm{~mm}^{3}$ at $72 \mathrm{~h}$ after ICH but not $24 \mathrm{~h}(23.10 \pm$ $\left.2.02 \mathrm{~mm}^{3}\right)(p<0.05$ vs. ICH + DMSO, $72 \mathrm{~h} ; p>0.05$ vs. $\mathrm{ICH}+\mathrm{DMSO}, 24 \mathrm{~h}$ ) (Additional file 2B). Consequently, the results indicated that ILG treatment $(20 \mathrm{mg} / \mathrm{kg})$ had no notably effect on bleeding but possibly promoted hematoma clearance after $\mathrm{ICH}$ induction.

\section{Intraperitoneal administration of ILG alleviated brain edema and disruption of BBB at 24 and $72 \mathrm{~h}$ after $\mathrm{ICH}$} After induction of $\mathrm{ICH}$ at 24 and $72 \mathrm{~h}, \mathrm{BWC}$ increased clearly ( $p<0.01$ vs. sham, 24 and 72 h) and Evans blue dyes significantly extravasated through disrupted BBB $(p<0.01$ vs. sham, 24 and $72 \mathrm{~h})$. The effects of ILG treatment on the brain edema and BBB disruption were in keeping with that on the behavioral deficits and brain tissue damages. Assessment of BWC using a wet/ dry weight method showed that ILG treatment at the dosage of $10 \mathrm{mg} / \mathrm{kg}$ (vehicle-DMSO vs. $10 \mathrm{mg} / \mathrm{kg}$ : $81.96 \pm 0.68 \%$ vs. $81.57 \pm 0.64 \%, p>0.05,24 \mathrm{~h} ; 81.40 \pm$ $0.73 \%$ vs. $81.05 \pm 0.90 \%, p>0.05,72 \mathrm{~h}$ ) was unable to improve brain edema, but the dosages at $20 \mathrm{mg} / \mathrm{kg}$ (vehicle-DMSO vs. $20 \mathrm{mg} / \mathrm{kg}$ : vs. $80.40 \pm 0.87 \%, p<0.01$, $24 \mathrm{~h}$; vs. $79.65 \pm 1.01 \%, p<0.01,72 \mathrm{~h})$ and $40 \mathrm{mg} / \mathrm{kg}$ (vehicle-DMSO vs. $40 \mathrm{mg} / \mathrm{kg}$ : vs. $80.07 \pm 0.43 \%, p<$ $0.01,24 \mathrm{~h}$; vs. $79.53 \pm 0.85 \%, p<0.01,72 \mathrm{~h})$ did play a positive role on the reduction of brain edema. However, there was no clear difference on the extent of protective effects about the ILG dosages of 20 and $40 \mathrm{mg} / \mathrm{kg}$ (20 vs. $40 \mathrm{mg} / \mathrm{kg}: p>0.05,24$ and $72 \mathrm{~h}$ ) (Fig. 1d, e). Quantitative measurements of EB dyes after extravasation in the ipsilateral hemisphere indicated that ILG treatment significantly alleviated the extravasation of EB dyes at the dosages of $20 \mathrm{mg} / \mathrm{kg}$ ( $p<0.01$ vs. vehicle-DMSO, 24 and $72 \mathrm{~h}$ ) and $40 \mathrm{mg} / \mathrm{kg}(p<0.01$ vs. vehicle-DMSO, 24 
A

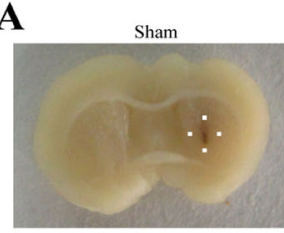

C sham
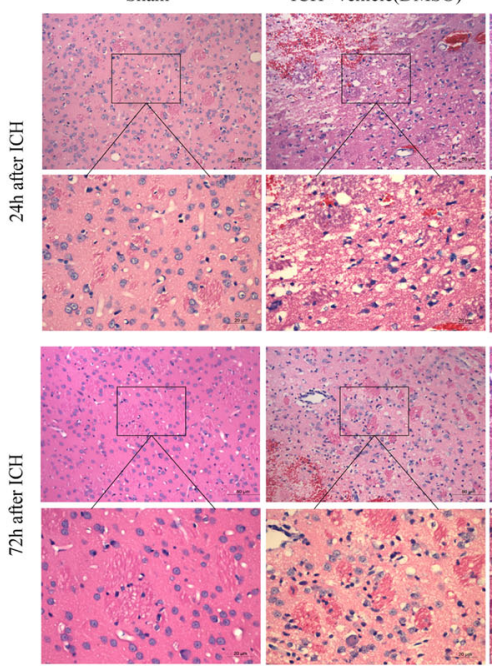

D

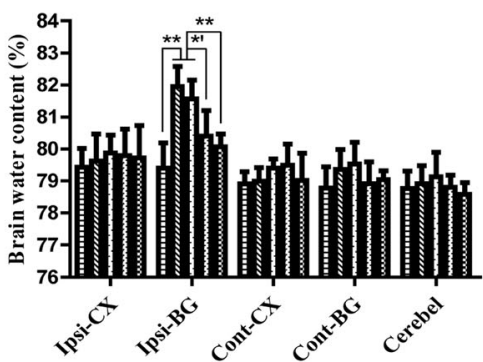

B

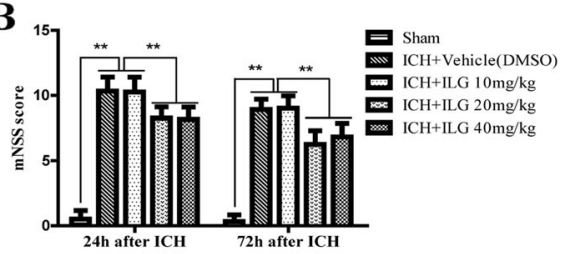

ICH+ILG $20 \mathrm{mg} / \mathrm{kg}$

ICH+ILG 40mg/kg

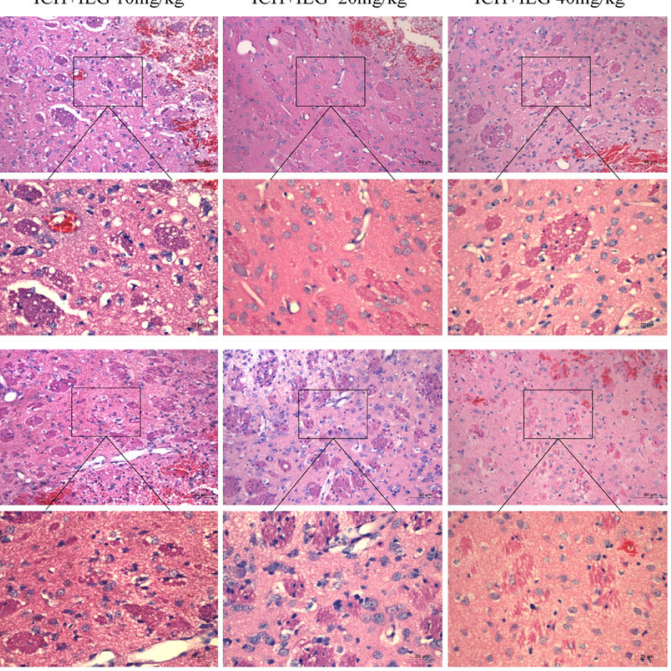

E

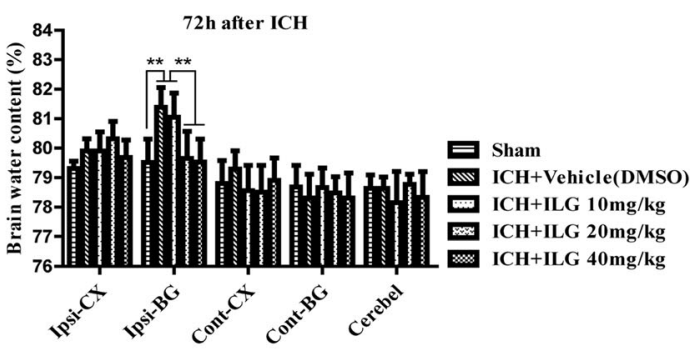

Fig. 1 Representative macrographs and the effects of ILG treatment on ICH-induced brain impairments (a-e). Typical macrographs (left: sham, $24 \mathrm{~h}$ after operation; right: $24 \mathrm{~h}$ after ICH induction) (a). ILG administration at the doses of 20 and $40 \mathrm{mg} / \mathrm{kg}$ at 24 and $72 \mathrm{~h}$ after ICH induction significantly reduced the neurological deficits assessed by a mNSS score scale (b) ( $n=12$ rats/group). Similarly, ILG treatment at doses of 20 and $40 \mathrm{mg} / \mathrm{kg}$ markedly alleviated the histological changes evaluated via H\&E staining (c) ( $n=6 \mathrm{rats} / \mathrm{group})$ and BWC (d, e) ( $n=6 \mathrm{rats} / \mathrm{group})$ measured by the dry/wet weight method at 24 and $72 \mathrm{~h}$ after ICH. Scale bar $=50$ and $20 \mu \mathrm{m}$. Values are shown as means \pm SD. ${ }^{* *} p<0.01$; ${ }^{*}$ : $\mathrm{ICH}+$ vehicle (DMSO) vs. ICH + ILG $20 \mathrm{mg} / \mathrm{kg}, p<0.01 ; \mathrm{ICH}+\mathrm{ILG} 10 \mathrm{mg} / \mathrm{kg}$ vs. ICH + ILG $20 \mathrm{mg} / \mathrm{kg}, p<0.05$

and $72 \mathrm{~h}$ ), but not $10 \mathrm{mg} / \mathrm{kg}(p>0.05$ vs. vehicleDMSO, 24 and $72 \mathrm{~h}$ ) after ICH modeling (Fig. 2a, b).

ILG administration decreased the number of degenerating neurons in the brain tissue surrounding the hematoma after ICH induction

To further estimate the effects of ILG treatment on brain damages in a rat ICH model, we assessed the neuronal degeneration in brain tissue of perihematomal region. $\mathrm{FJC}^{+}$neurons were significantly increased in the brain tissue surrounding hematoma after ICH $(p<0.01$ vs. sham, 24 and $72 \mathrm{~h}$ ) and administration of ILG at the dosages of $20 \mathrm{mg} / \mathrm{kg}$ ( $p<0.01$ vs. vehicle-DMSO, 24 and
$72 \mathrm{~h})$ and $40 \mathrm{mg} / \mathrm{kg}(p<0.01$ vs. vehicle-DMSO, 24 and $72 \mathrm{~h})$ markedly dropped the number of $\mathrm{FJC}^{+}$cells. Additionally, a $10 \mathrm{mg} / \mathrm{kg}$ dosage of ILG treatment had no distinct effect on the reduction of degenerating neurons ( $p>0.05$ vs. vehicle-DMSO, 24 and $72 \mathrm{~h}$ ) and treatment results of ILG between 20 and $40 \mathrm{mg} / \mathrm{kg}$ were similar (20 vs. $40 \mathrm{mg} / \mathrm{kg}: p>0.05,24$ and $72 \mathrm{~h}$ ) (Fig. $2 \mathrm{c}, \mathrm{d}$ ).

In conclusion, experimental results displayed above clearly suggested that ILG treatment by intraperitoneal delivery significantly reduced the behavioral deficits, histological impairments, BBB disruption, brain edema and degenerating neurons of perihematomal brain tissue at the doses of 20 and $40 \mathrm{mg} / \mathrm{kg}$, but there were no 

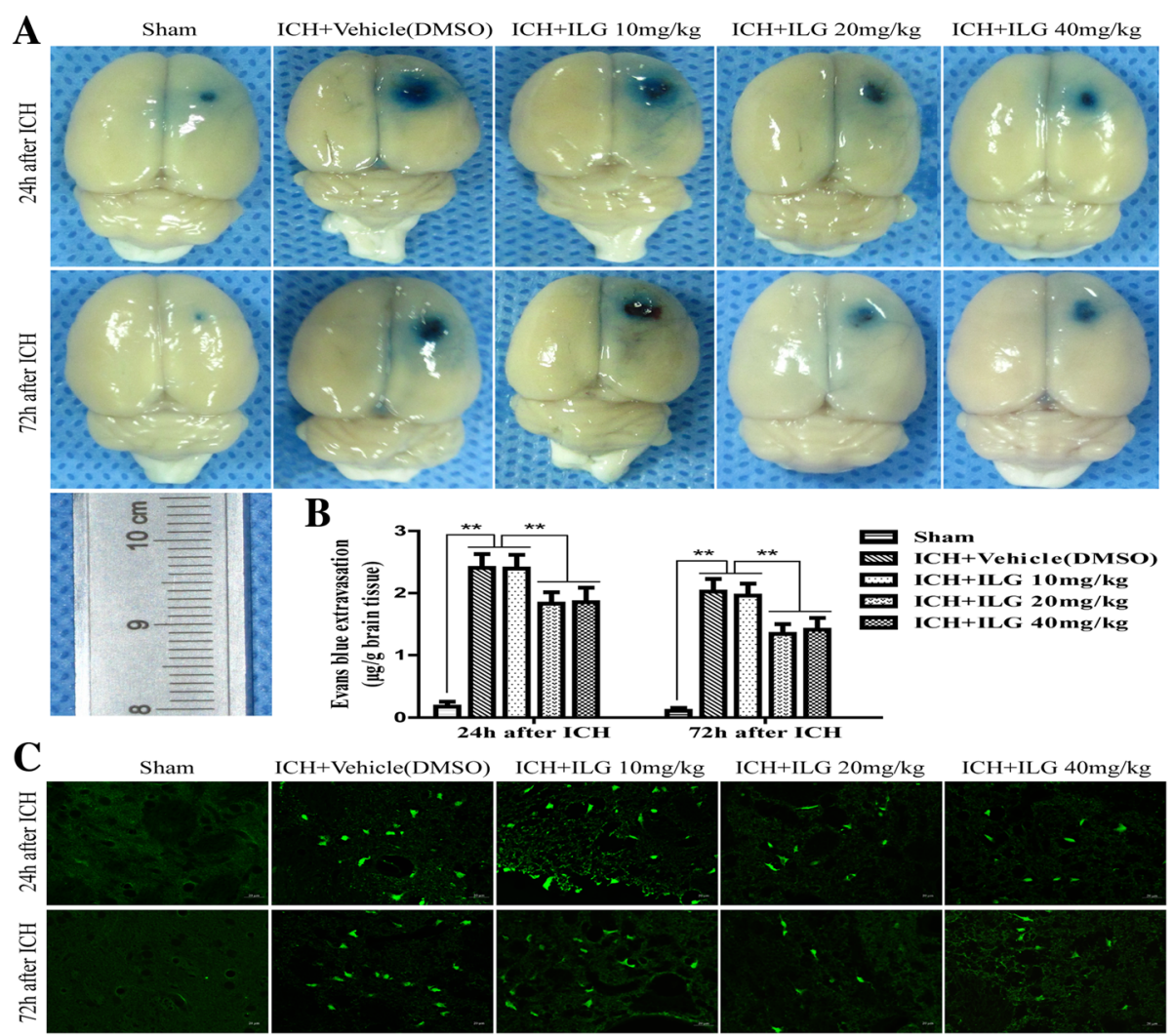

D

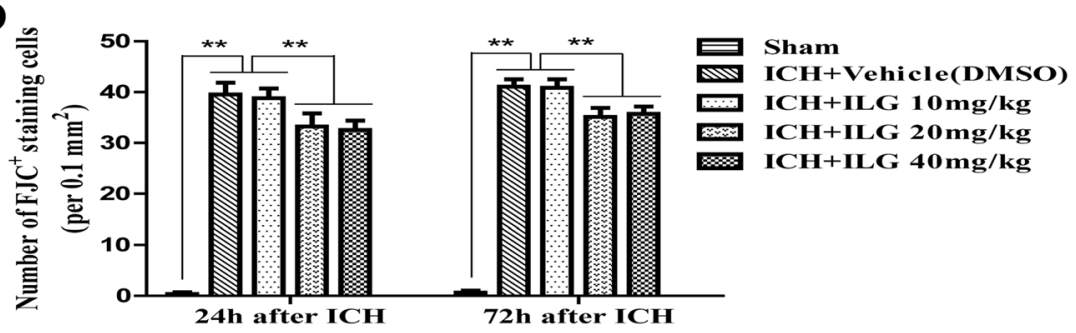

Fig. 2 Effects of ILG on BBB disruption and the number of degenerating neuron following ICH (a-d). ILG administration at the dosages of 20 and 40 mg/ $\mathrm{kg}$ significantly alleviated the extravasation of EB dyes and the number of $\mathrm{FJC}^{+}$staining cells. Macroscopic images of brains with extravasated EB dyes (a) and corresponding quantitative analyses (b) ( $n=6$ rats/group). Typical microscopic images for FJC ${ }^{+}$staining cells from injury brain tissues (c) and quantitative analyses of the number of FJC ${ }^{+}$staining cells (d) $\left(n=6\right.$ rats/group). Scale bar $=20 \mu \mathrm{m}$. Values are reported as means \pm SD. ${ }^{* *} p<0.01$

obvious difference on the extent between them. Thus, we selected the dosage of $20 \mathrm{mg} / \mathrm{kg}$ to further explore the potential molecular mechanisms of ILG's protective effects on early brain injury after ICH induction.

The expression and nuclear translocation of Nrf2 was promoted by ILG treatment at $24 \mathrm{~h}$ after ICH induction and that of NF-KB p65 was suppressed

ILG was reported to hold capacity to activate the Nrf2mediated antioxidant system and inhibit the activation of NF- $\mathrm{kB}$. Thus, we guessed that whether ILG alleviated early brain injury post ICH involved in Nrf2 and NF- $\mathrm{kB}$ pathways. In order to verify our supposition, we performed WB analyses and IHC staining using the perihematomal brain tissue at $24 \mathrm{~h}$ after ICH and the results suggested that ILG $20 \mathrm{mg} / \mathrm{kg}$ treatment significantly increased the expression of total Nrf2 protein $(p<0.01$ vs. ICH) (Fig. $3 \mathrm{a}$, d) and decreased that of total NF-kB p65 protein $(p<0.01$ vs. ICH) (Fig. 3a, b). Typical IHC images were obtained from the injury brain tissue (Fig. 4). Meanwhile, Nrf2 protein level in the cytoplasm was significantly dropped $(p<0.01$ vs. ICH) (Fig. 3a, e) and notably increased in the nucleus $(p<0.01$ vs. ICH) (Fig. 3a, g); cytoplasmic level of NF-kB p65 was significantly increased ( $p<0.01$ vs. ICH) (Fig. 3a, c) and the nuclear level was notably deceased $(p<0.01$ vs. ICH) (Fig. 3a, f). Consequently, experimental results indicated that ILG promoted the expression and nuclear translocation of Nrf2 and suppressed that of NF-kB p65. 


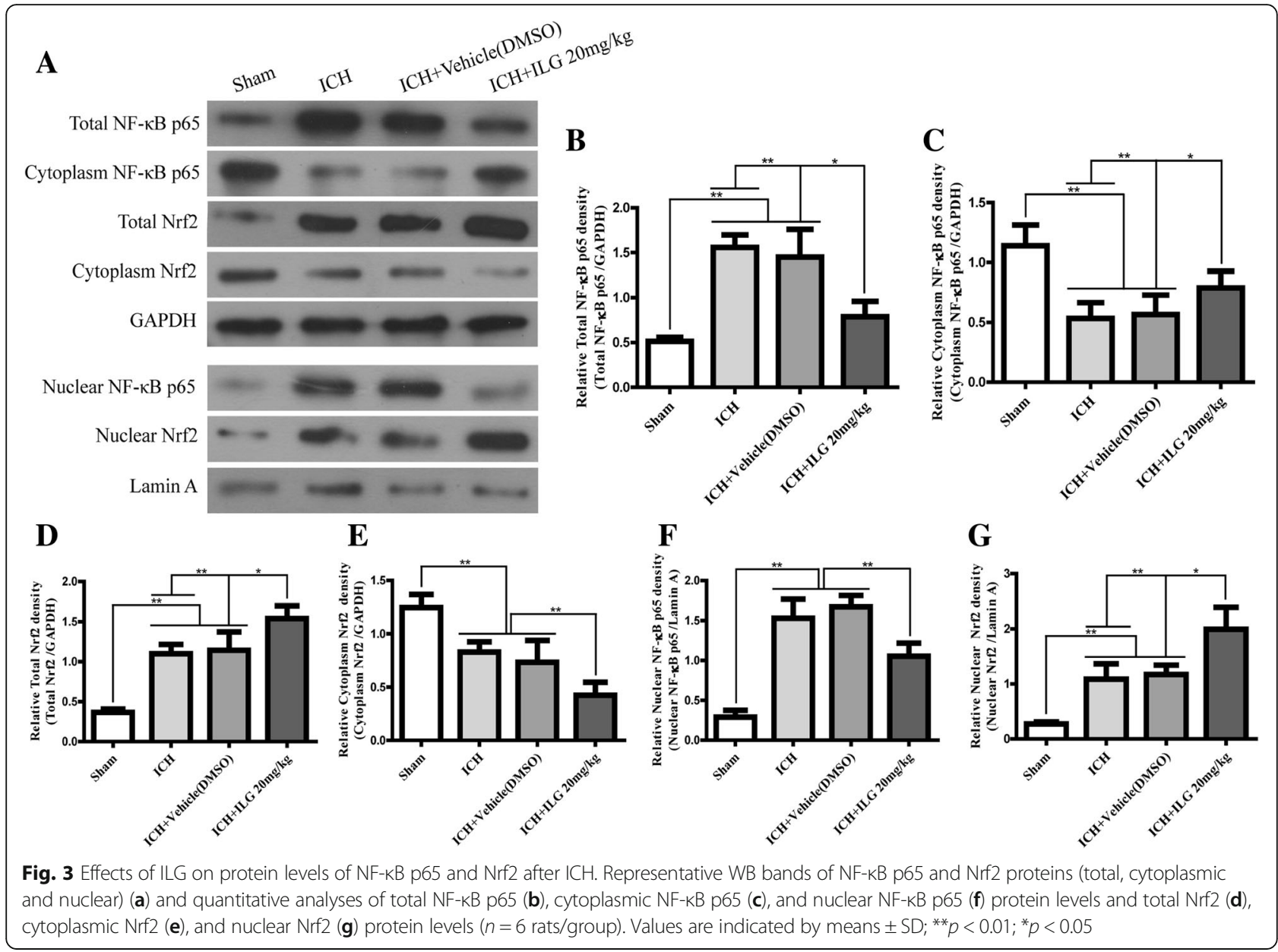

The components of NLRP3 inflammasome pathway and subsequent IL-1 $\beta /$ IL-18 release were suppressed by ILG treatment

Activation of NLRP3 inflammasome and induction of its components aggravated the early brain injury after $\mathrm{ICH}$, and blockades were protective reported by our [17] and other studies $[8,16]$. In addition, a recent study showed that Nrf2 negatively regulates NLRP3 inflammasome activity by inhibiting ROS [18]. Therefore, we investigated that whether ILG decreased the activation and induction of NLRP3 inflammasome pathway components or not. The results showed that ILG at the dosage of $20 \mathrm{mg} / \mathrm{kg}$ significantly suppressed the expression of NLRP3 inflammasome components: NLRP3, ASC, caspase-1 $(p<0.01$ vs. ICH) (Fig. 5a, b, c, e), and blocked the activation of NLRP3 inflammasome as indicated by the reduction of cleaved IL-1 $\beta$ and IL-18 ( $p<0.01$ vs. ICH) (Fig. 5a, g, i). Representative IHC images of NLRP3 protein were shown (Fig. 4). Consistent with the above results, ILG treatment obviously reduced the protein levels of proIL-1 $\beta$ ( $p<0.01$ vs. ICH) (Fig. 5a, f) and pro-IL-18 ( $p<$ 0.01 vs. ICH) (Fig. $5 \mathrm{a}, \mathrm{h}$ ) and increased the expression of pro-caspase-1 ( $p<0.05$ vs. ICH) (Fig. $5 \mathrm{a}, \mathrm{d}$ ).
ILG delivery reduced the markers of oxidative stress injury, infiltration of $\mathrm{MPO}^{+}, \mathrm{CD}^{+} 8^{+}, \mathrm{Iba}^{-1}{ }^{+}$cells, and expression of MPO in the brain tissue surrounding the hematoma

Excessive production of ROS mediates seriously oxidative injury and is a key promoting factor for the activation of NLRP3 inflammasome, and the antioxidant responses initiated through nuclear translocation of Nrf2 could alleviate the ROS-induced brain injury and inflammatory cell infiltration. Therefore, we probed that if ILG treatment at $20 \mathrm{mg} / \mathrm{kg}$ dropped the production of oxidative stress markers 3-NT and 8-OHdG by IHC staining and infiltration of neutrophils (indicated by MPO, a neutrophil marker) using IF staining and WB analyses. The results suggested that ILG $(20 \mathrm{mg} / \mathrm{kg})$ could significantly decrease the amounts of $3-\mathrm{NT}^{+}$cells $(p<0.01$ vs. ICH) (Fig. 6a, b), 8-OHdG ${ }^{+}$cells $(p<0.05$ vs. ICH) (Fig. 6a, c) in perihematomal brain tissues. Also, the expression level of MPO was notably decreased in the injury brain tissue $(p<0.01$ vs. ICH) (Fig. 7c), and representative IF images and WB band of MPO protein were shown, respectively (Fig. 7a, b). Meanwhile, ILG (20 mg/kg) could significantly drop the amounts of $\mathrm{CD}^{+} 8^{+}$, Iba- $1^{+}(\mathrm{CD} 68$ 


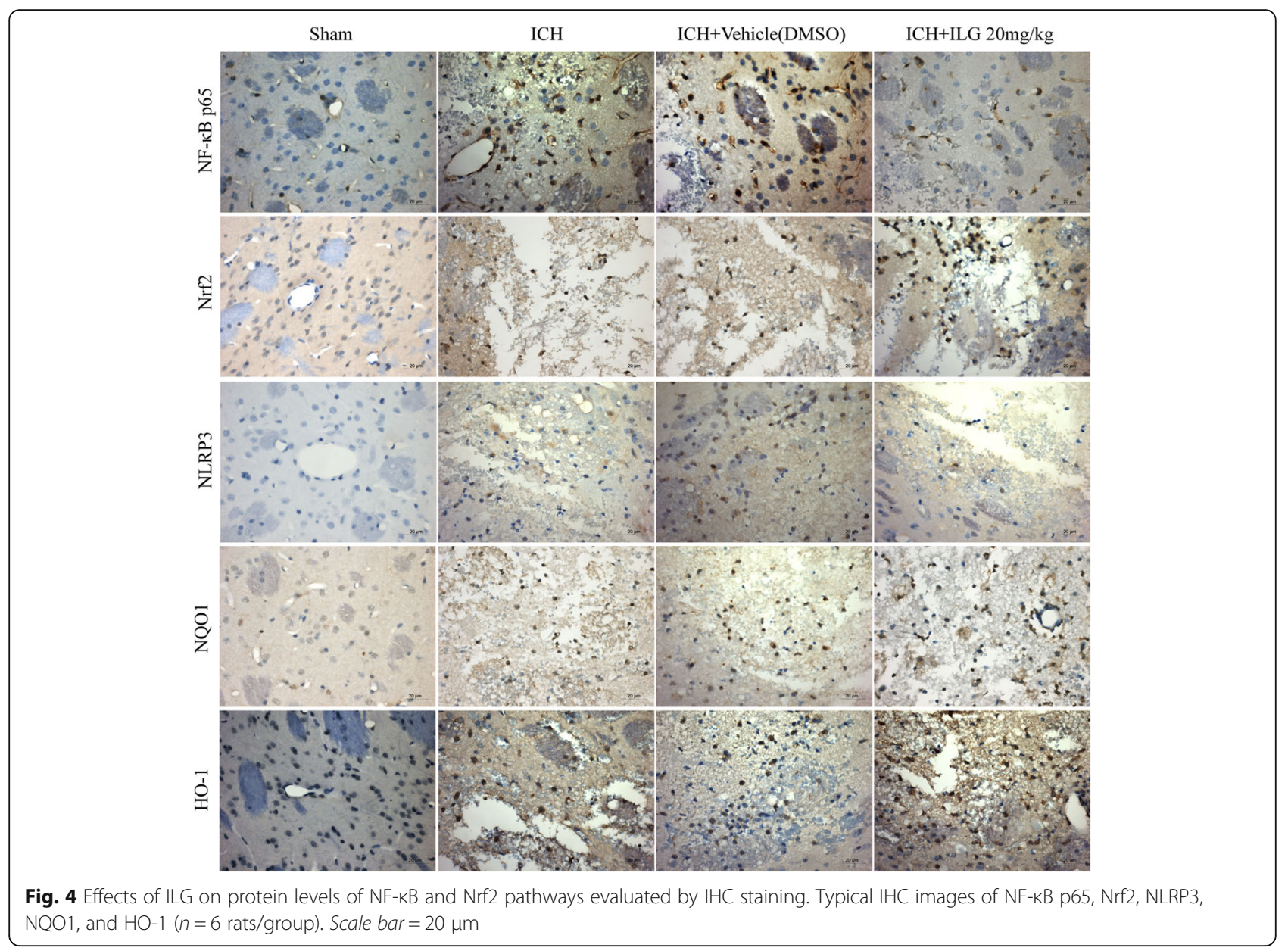

and Iba-1, the microglia/macrophage markers) cell recruitments in injury brain tissue after ICH as well ( $p<0.05$ vs. ICH) (Additional file 2C, D, E).

\section{ILG treatment lowered the mRNA levels of NLRP3} inflammasome, NF-KB, and Nrf2 pathway components

To further explore the effects of ILG treatment on the mRNA levels of NLRP3 inflammasome, NF- $\mathrm{kB}$, and $\mathrm{Nrf} 2$ pathway components at $24 \mathrm{~h}$ after ICH induction, we performed relative real-time RT-qPCR study. The results showed that $24 \mathrm{~h}$ after $\mathrm{ICH}$ induction, the mRNA levels of NLRP3, ASC, caspase-1, IL-1 $\beta$, IL-18, NQO1, and HO-1 were obviously increased $(p<0.01$ vs. sham) (Fig. 8) and ILG (20 mg/kg) significantly weakened the increases of NLRP3, caspase-1, IL-18 $(p<$ 0.05 vs. ICH) (Fig. 8a, c, e), ASC, and IL-1 $\beta$ mRNA levels $(p<0.01$ vs. ICH) (Fig. 8b, d). Meanwhile, NQO1 $(p<0.01$ vs. ICH) (Fig. 8f) and HO-1 ( $p<0.05$ vs. ICH) (Fig. 8g) were further distinctly upregulated at the mRNA levels by ILG treatment. In addition, representative IHC images of NQO1 and HO-1 proteins were shown (Fig. 4).
Inflammatory cytokine levels in the brain tissue and serum from the blood of cardiac puncture were both significantly reduced by ILG treatment

We measured the levels of inflammatory cytokines IL$1 \beta$ and IL-18 both in perihematomal brain tissues and the serum, respectively. The results were similar to the previous experimental findings, namely, ILG treatment significantly dropped the levels of IL-1 $\beta$ in damaged brain tissues and the serum ( $p<0.01$ vs. ICH) (Fig. 8 h, i). The contents of IL-18 in the damaged brain tissue and serum were significantly decreased as well $(p<0.01$ vs. ICH) (Fig. 8j, k).

ILG reduced the contents of ROS and GSSG, increased the level of GSH and upregulated the enzyme activities of SOD and CAT

We also detected the activities of SOD and CAT enzymes and the contents of GSH/GSSG and ROS after ILG treatment at $24 \mathrm{~h}$ post $\mathrm{ICH}$. Experimental results indicated that after ICH induction, enzyme activities of CAT and SOD and the content of GSH were significantly decreased $(p<$ 0.01 vs. sham) (Fig. 8l, m, o), the levels of GSSG and ROS were evidently increased ( $p<0.01$ vs. sham) (Fig. 8o, n). 


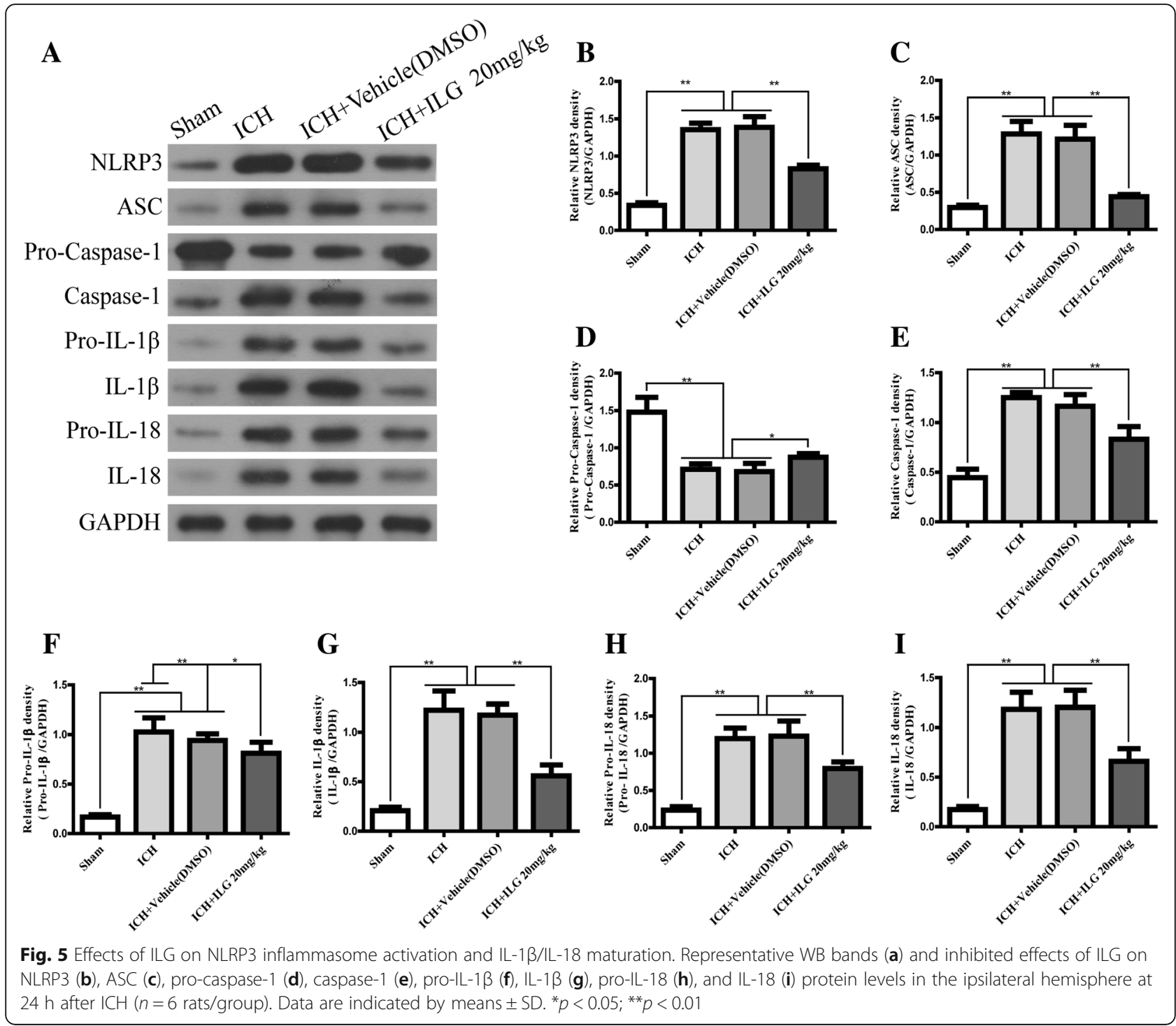

ILG treatment at $20 \mathrm{mg} / \mathrm{kg}$ could strikingly reverse the decreases of CAT and SOD enzyme activities, increases of GSSG and ROS levels, and reduction of GSH content $(p<0.01$ vs. ICH) (Fig. 8l-o).

\section{Nrf2 siRNA interference aggravated the behavioral} deficits and brain edema and raised the number of $\mathrm{FJC}^{+}$ cells and administration of ILG lowered those uncomfortable effects

In our studies mentioned above, some preliminary conclusions were obtained that ILG could effectively reduce the early brain injury after ICH induction and the protective effects of ILG might be involved in the regulation of Nrf2, ROS, NF-kB, and NLPR3 inflammasome pathways. We wondered if ILG treatment reduced the brain injury mediated by NLRP3 inflammasome pathway via Nrf2 activation-induced ROS and/or NF-kB inhibition.
We conducted the Nrf2 siRNA interfering and Nrf2 siRNA together with ILG $20 \mathrm{mg} / \mathrm{kg}$ co-treatment research by intraventricular injection and intraperitoneal delivery, respectively. Interfering effects of Nrf2 siRNA were identified using real-time RT-qPCR and WB analyses. The results showed that Nrf2 siRNA significantly dropped the mRNA and protein expression $(p<0.01$ vs. vehicle-2) levels of Nrf2 (Fig. 9a-c). In the study, we found that Nrf2 siRNA interference markedly exacerbated the function deficits (Nrf2 siRNA vs. vehicle-2: $13.67 \pm 0.91$ vs. $10.89 \pm 0.96, p<0.01$ ) (Fig. 9d) and brain edema (Nrf2 siRNA vs. vehicle-2: $83.57 \pm 0.80 \%$ vs. $82.35 \pm 0.98 \%, p<0.05$ ) (Fig. 9f) and increased the amounts of degenerating neuronal cells $(p<0.01$ vs. vehicle-2) (Fig. 9e, g) at $24 \mathrm{~h}$ after ICH induction. However, ILG administration $(20 \mathrm{mg} / \mathrm{kg})$ distinctly reversed those uncomfortable results: function deficits (Nrf2 


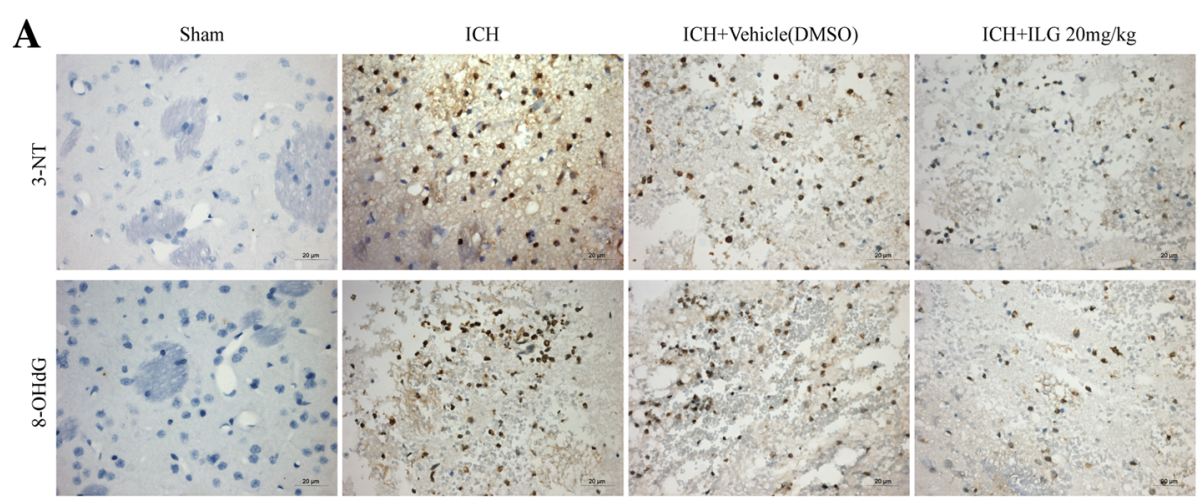

B

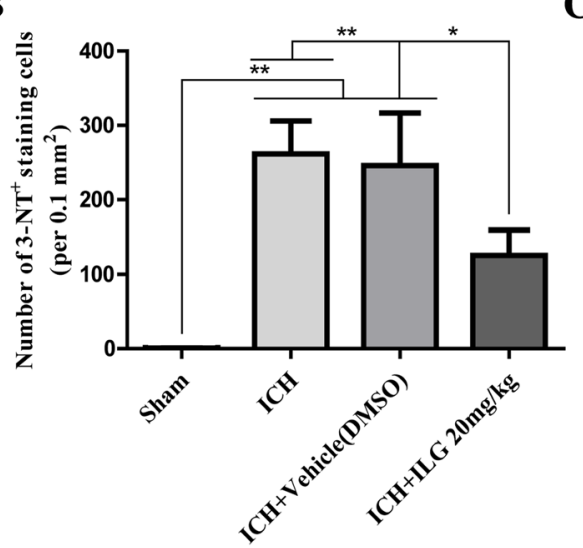

C

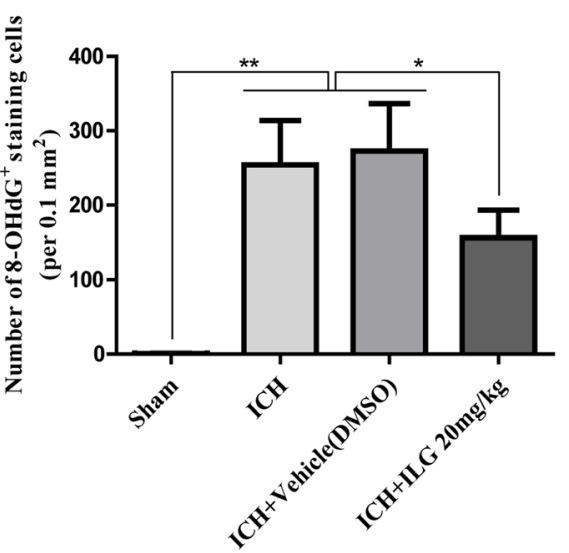

Fig. 6 Effects of ILG on oxidative stress marker levels in the injury brain tissue after ICH. ILG significantly decreased the oxidative stress marker levels (3-NT and 8-OHdG) after ICH. Typical oxidative stress markers 3-NT and 8-OHdG IHC images (a) and quantitative analyses $(\mathbf{b}, \mathbf{c})(n=6$ rats/group). Scale bar $=20 \mu \mathrm{m}$. Values are reported as means \pm SD. ${ }^{* *} p<0.01 ;{ }^{*} p<0.05$

siRNA vs. Nrf2 siRNA + ILG $20 \mathrm{mg} / \mathrm{kg}:$ vs. $11.89 \pm 0.90$, $p<0.01$ ), brain edema (Nrf2 siRNA vs. Nrf2 siRNA + ILG $20 \mathrm{mg} / \mathrm{kg}$ : vs. $82.27 \pm 0.57 \%, p<0.05)$, and $\mathrm{FJC}^{+}$cells $(p<0.01$ vs. Nrf2 siRNA) (Fig. 9d-g).

Nrf2 siRNA interference increased the expression of NF-KB p65 and NLRP3 inflammasome components and triggered the activation of NLRP3 inflammasome pathway and ILG reduced these effects

We further evaluated the effects of Nrf2 siRNA on the expression of NF-kB p65 and induction and activation of NLRP3 inflammasome pathway components. We found that Nrf2 siRNA interfering could significantly increase the expression of NF- $\mathrm{kB}$ p65 $(p<0.05$ vs. vehicle-2) (Fig. 10a, b); NLRP3 inflammasome components: NLRP3, ASC, caspase- 1 , and downstream molecule, IL-1 $\beta$ ( $p<$ 0.01 vs. vehicle-2) (Fig. 10a, c, d, e, f). ILG at the dosage of $20 \mathrm{mg} / \mathrm{kg}$ and Nrf2 siRNA co-administration obviously alleviated the enhancement of protein expression levels of NF-kB p65, caspase-1, IL-1 $\beta$ ( $p<0.05$ vs. Nrf2 siRNA) (Fig. 10a, b, e, f), NLRP3, and ASC ( $p<0.01$ vs. Nrf2 siRNA) (Fig. 10a, c, d) after Nrf2 siRNA treatment at $24 \mathrm{~h}$ following $\mathrm{ICH}$.

\section{Discussion}

Accumulating studies have displayed that oxidative stress and inflammation played key roles in the pathophysiological processes of early brain injury after $\mathrm{ICH}$ induction and inhibition of them were beneficial $[5,7,44-46]$. In our first experiment, we found that ILG administration at the dosages of 20 and $40 \mathrm{mg} /$ $\mathrm{kg}$ ameliorated the early brain tissue impairments and behavioral defects as indicated by the reduction of mNSS scores and $\mathrm{FJC}^{+}$neuronal cells, the improvement of histological damages, BBB disruption, and brain edema at 24 and $72 \mathrm{~h}$ post ICH modeling and obtained the ideal dose of ILG at $20 \mathrm{mg} / \mathrm{kg}$ for the following experiments. In the second experiment, the results showed that ILG delivery at $20 \mathrm{mg} / \mathrm{kg}$ activated the Nrf2-mediated antioxidative signaling pathway and suppressed the activation of NF- $\mathrm{kB}$ and NLRP3 inflammasome pathways as indicated by the increasing of nuclear translocation and decreasing of the cytoplasmic level of $\mathrm{Nrf} 2$, the reduction of nuclear translocation and upregulation of cytoplasmic level of NF- $\mathrm{kB}$ $\mathrm{p} 65$, and the induction and activation of NLRP3 inflammasome (components) and its downstream molecules. In the third experiment, we found that Nrf2 siRNA notably 

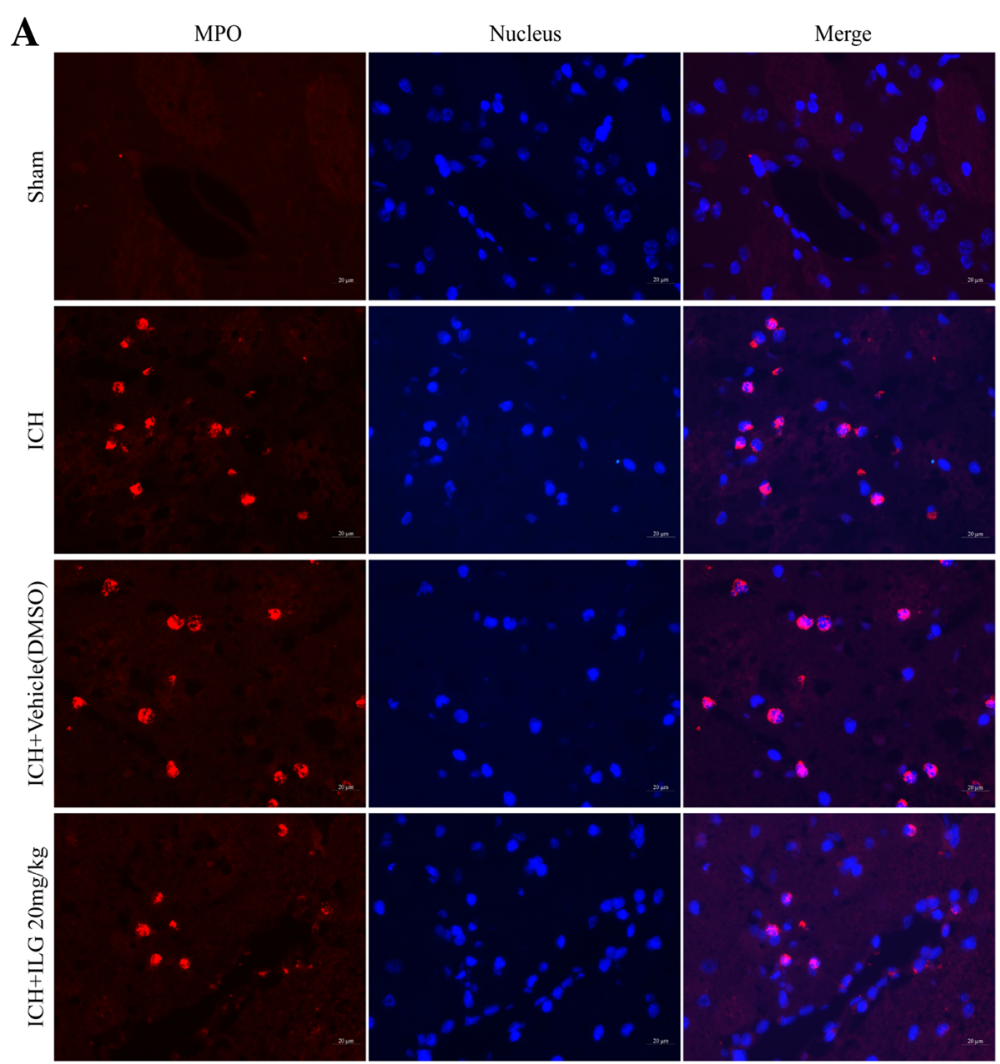

$\mathbf{B}$

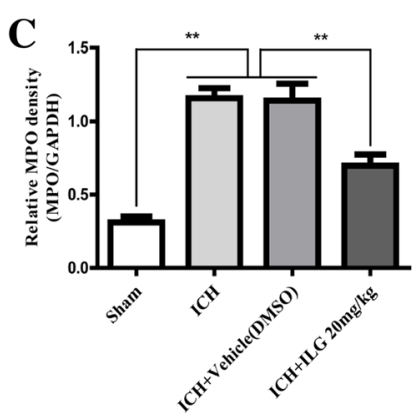

Fig. 7 Effects of ILG on the number of $\mathrm{MPO}^{+}$cells in perihematomal brain tissues (a-c). Representative microscopic images (a), WB bands (b), and quantitative analysis of the bands (c) $\left(n=6\right.$ rats/group). Scale bar $=20 \mu \mathrm{m}$. Values are reported as means \pm SD. ${ }^{* *} p<0.01$

exacerbated the early brain injury post $\mathrm{ICH}$ as supported by aggravated behavioral deficits, brain edema, and degeneration of neuronal cells, and ILG treatment visibly alleviated the effects. Based on the results above, we hypothesized here that ILG alleviates early brain injury after $\mathrm{ICH}$ induction by activating Nrf2 antioxidant pathway, inhibiting the activation and induction of NLRP3 inflammasome (components), and this process may be involved in the suppression of ROS and/or NF- $\mathrm{BB}$ signaling pathways. Potential molecular mechanisms of ILG's effects on the early brain injury after $\mathrm{ICH}$ induction is shown in Additional file 3.

Results from our study have powerful evidence showing that ILG possesses a brain cell-protective function, and this was in line with previous studies in vivo [47-50] and in vitro $[26,51,52]$. Pretreatment of ILG significantly alleviated neurological deficits, cerebral infarct, and brain edema, and these neuroprotective effects are involved in the increases of brain ATP content, energy charge (EC) and total adenine nucleotides (TAN) and preservation of brain $\mathrm{Na}^{+} \mathrm{K}^{+}$ATPase activity, SOD, CAT, and GSH-Px, and inhibition of the increase of brain MDA content in a rat cerebral ischemia-reperfusion model [50]. Toxicity of brain cells induced by cocaine and methamphetamine delivery was also able to be attenuated by ILG treatment [47-49]. Consistently, in in vitro studies, ILG protected neuronal cells from glutamate and 6-hydroxydopamine (6-OHDA)-induced neurotoxicity by reducing the production of ROS [51, 52]. Meanwhile, a recent report also showed that ILG treatment could notably alleviate 

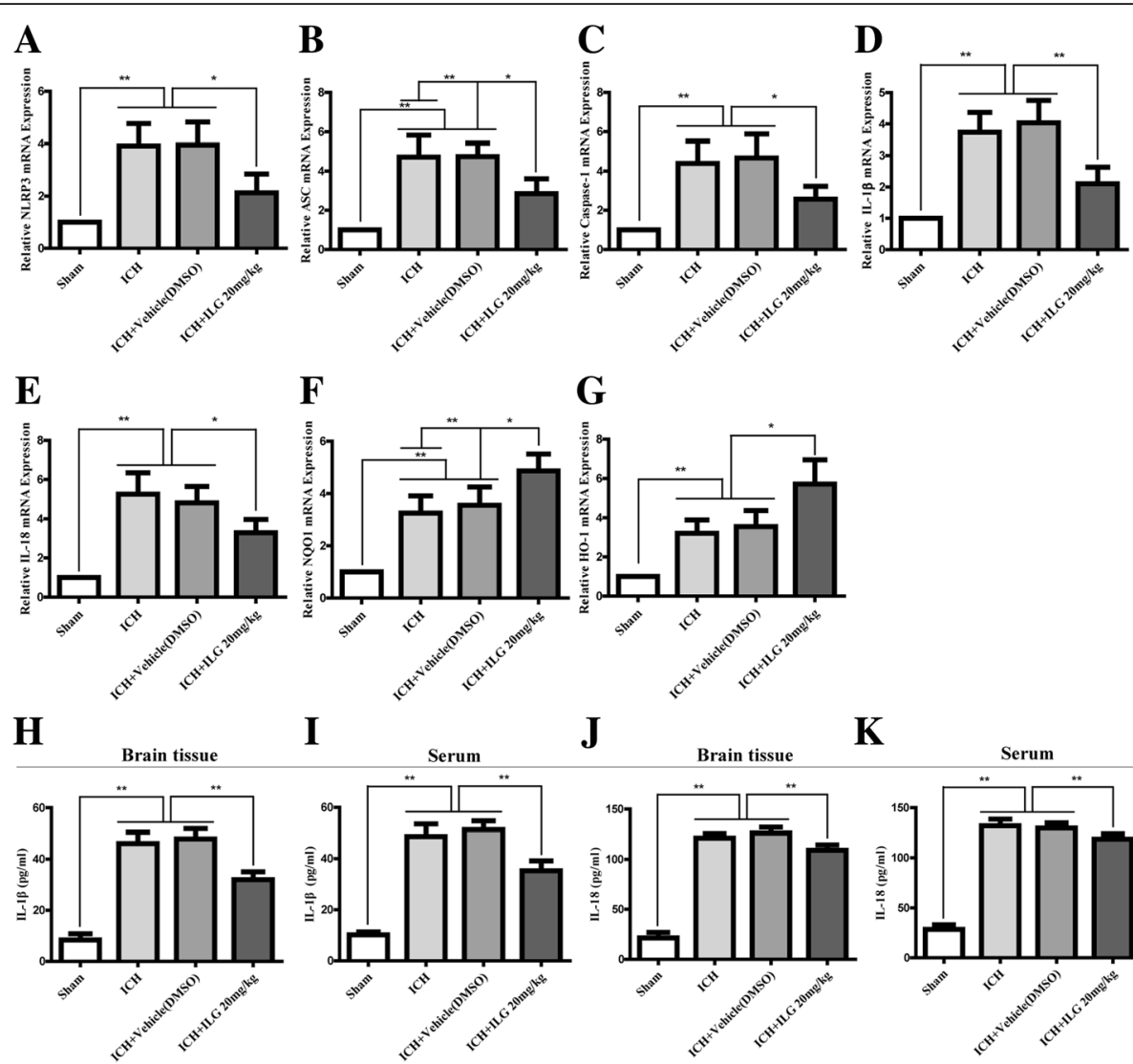

$\mathbf{K}$

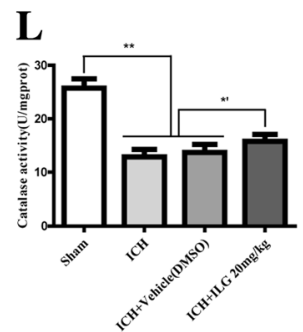

$\mathbf{M}$

$\mathbf{N}$
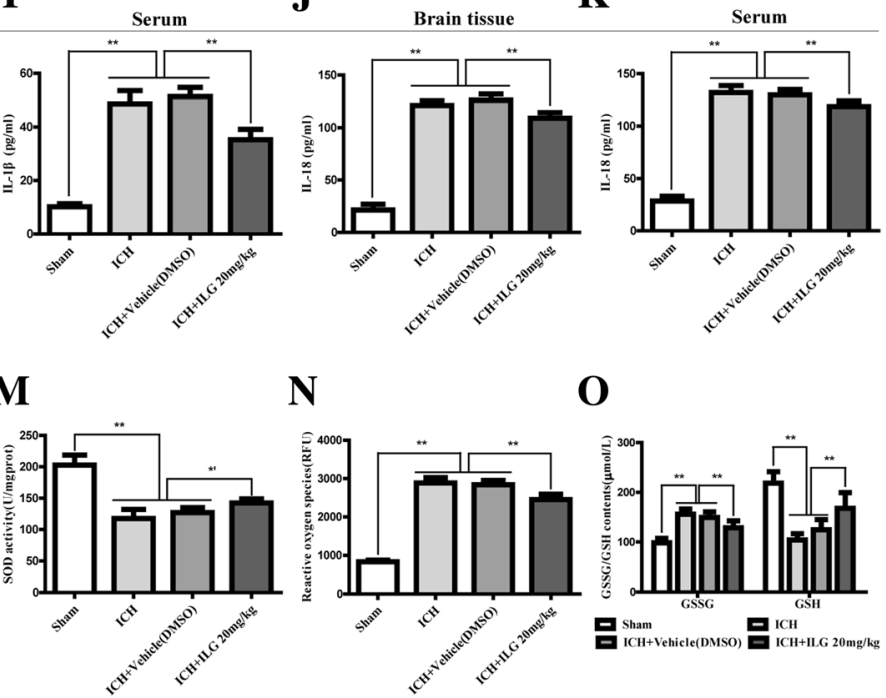

$\mathbf{O}$

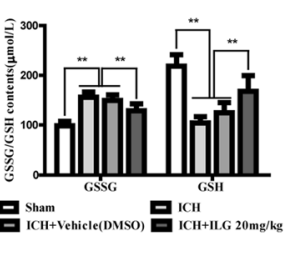

Fig. 8 Effects of ILG on the mRNA levels of NLRP3 inflammasome pathway components and downstream molecules of Nrf2-mediated antioxidant system, contents of inflammatory cytokines and antioxidants, and activity of antioxidative enzymes. ILG treatment at $20 \mathrm{mg} / \mathrm{kg}$ notably decreased the mRNA levels of NLRP3 (a), ASC (b), caspase-1 (c), IL-1ß (d), IL-18 (e), and further increased the NQO1 (f), HO-1 (g) mRNA levels ( $n=6$ rats/ group). Similarly, ILG administration at $20 \mathrm{mg} / \mathrm{kg}$ obviously reduced the levels of IL-1 $\beta$ (h, i) and IL-18 (j, $\mathbf{k}$ ) in the perihematomal brain tissue and serum measured by ELISA ( $n=6$ rats/group). Besides, ILG delivery also markedly reversed the reduction of CAT and SOD activities (I, $\mathbf{m})$, increasing of ROS (n) and GSSG (o) contents and decreasing of GSH level (o) ( $n=6$ rats/group). Values are reported as means \pm SD. ${ }^{* *} p<0.01 ;{ }^{*} p<0.05 ;{ }^{*}$ : ICH vs. ICH + ILG $20 \mathrm{mg} / \mathrm{kg}, p<0.01 ; \mathrm{ICH}+$ vehicle (DMSO) vs. ICH + ILG $20 \mathrm{mg} / \mathrm{kg}, p<0.05$

rotenone and sodium nitroprusside (SNP)-induced oxidative stress and nitrosative stress by improving MMP, ATP levels, and neural cell viability [26].

ILG, one of the active extracts isolated from G. uralensis, is a flavonoid with chalcone structure and is brainpermeable after administration [53], which showed various biological activities including anti-inflammatory, antioxidative stress [9]. Increasing studies suggested that ILG exerts biological effects by activating Nrf2-mediated antioxidative system and eliminating ROS [9] and was the most potent inducer to stimulate the expression of Nrf2 and its downstream genes [28]. The activation mechanisms of Nrf2 by ILG might be involved in the alkylation of kelchlike ECH-associated protein 1 (Keap1) at specific cysteine residues, especially at the site of $\mathrm{C} 151$, a most reactive cysteine residue site of human Keap1 [54]. At the same time, there were reports showing that ILG upregulated the expression of HO-1 in RAW264.7 macrophages through the extracellular signal-regulated kinase1/2 (ERK1/2) pathway post lipopolysaccharide (LPS) treatment [55] and had inhibitory effects on LPS-induced inflammatory responses of mouse macrophages by suppressing NF- $\mathrm{kB}$ signaling 

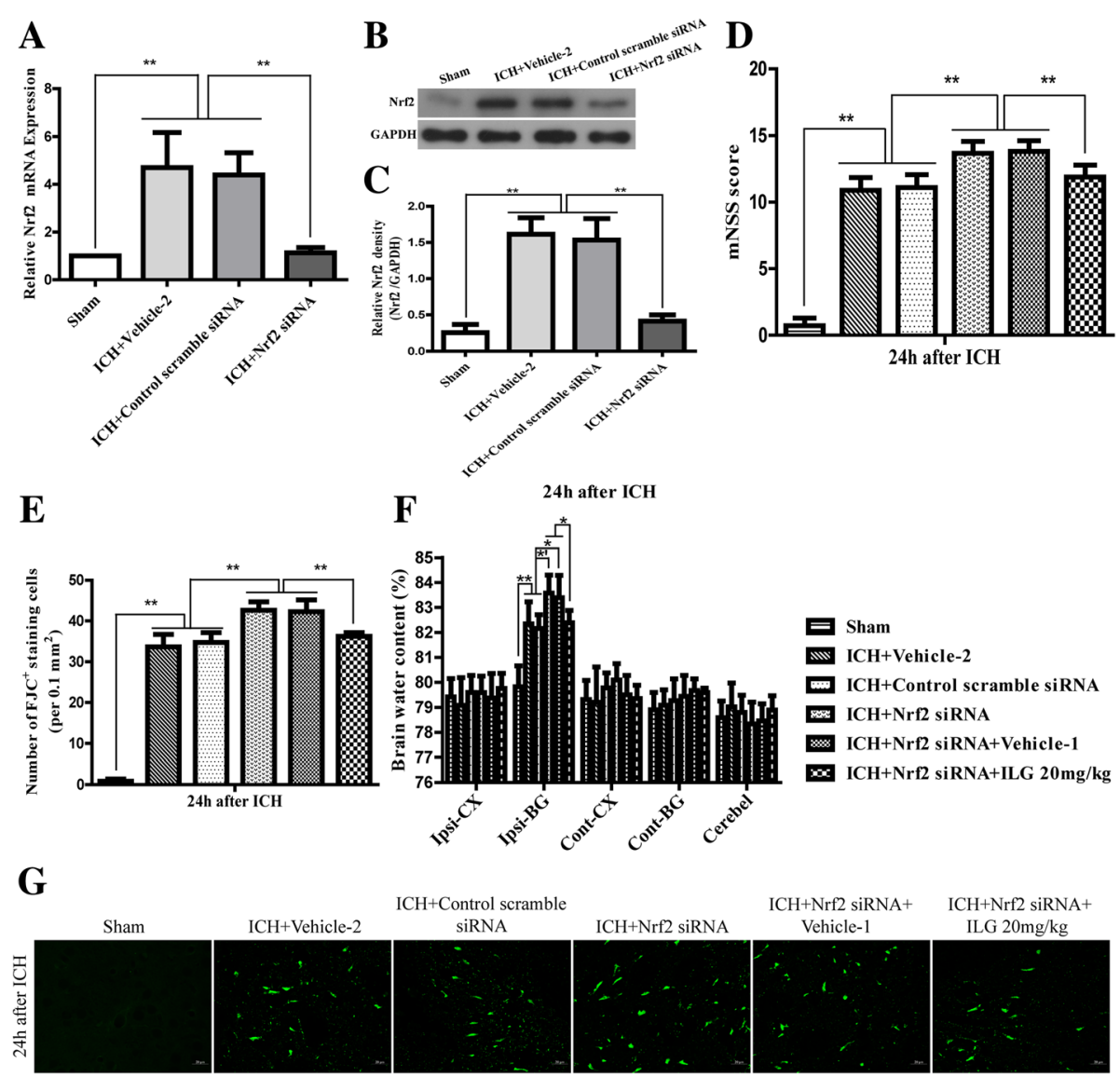

Fig. 9 Effects of Nrf2 siRNA delivery and Nrf2 siRNA with ILG 20 mg/kg co-administration in ICH rats. Real-time RT-qPCR assay of Nrf2 after siRNA delivery $24 \mathrm{~h}$ following ICH ( $n=6$ rats/group) (a). WB assay (b) and quantification (c) of Nrf2 protein after siRNA treatment $24 \mathrm{~h}$ following ICH ( $n=6$ rats/group); mNSS score (d) at $24 \mathrm{~h}$ post ICH ( $n=18$ rats/group). BWC (f) at $24 \mathrm{~h}$ after $\mathrm{ICH}\left(n=6\right.$ rats/group). FJC staining $(\mathbf{g})$ and quantification $(\mathbf{e})$ of FJC $\mathrm{C}^{+}$staining cells $\left(n=6\right.$ rats/group). Data represent means \pm SD. Scale bar $=20 \mu \mathrm{m}$. ${ }^{* *} p<0.01 ;{ }^{*} p<0.05$. ${ }^{*}$ : ICH + vehicle-2 vs. ICH + Nrf2 siRNA, $p<0.05 ; \mathrm{ICH}+\mathrm{control}$ scramble siRNA vs. ICH + Nrf2 siRNA, $p<0.01$

involved in the blockade of inhibitor of $\kappa B \alpha(\mathrm{I} \kappa \mathrm{B} \alpha)$ degradation and phosphorylation [56]. In addition, recent reports also indicated that ILG induced the activation of Nrf2 as indicated by an increase in its nuclear translocation and the expression of Nrf2-targeted phase II enzymes, such as HO-1 and NQO1 [29]. In addition to the regulation of ILG on Nrf2 pathway, increasing evidences have suggested that ILG notably inhibited the activation of NF-kB pathway by suppressing LPS-induced TLR4/MD-2 homodimerization [57], blocking I $K B \alpha$ phosphorylation and degradation, reducing NF- $\mathrm{kB}$ p65 nuclear translocation [58], downregulating mRNA and protein levels of NF- $\mathrm{kB}$ and its activation $[25,59]$, and inhibiting RANKL-stimulated NF-кB expression and nuclear translocation [23].

The NLRP3 inflammasome, a best characterized pattern recognition receptor (PRR) in innate immune response, played a crucial component in the early brain injury post ICH $[8,16,17]$ and was composed by a sensor (NLRP3 protein), an adaptor (ASC protein), and an effector (zymogen pro-caspase-1) [60, 61]. Production of ROS, mitochondrial DNA or the mitochondrial phospholipid cardiolipin, potassium efflux, changes in cell volume, calcium, and lysosomal impairments have all been proposed as critical active signals to trigger the activation of NLRP3 inflammasome [60, 61]. Activation of NLRP3 inflammasome demands two signals. One is the stimulus of NF-kB pathway that after NF- $\mathrm{kB}$ activation, NF- $k B$ translocates into the nucleus, after binding with DNA and initiating the transcription and translation of IL-1 $\beta$ precursor protein and NLRP3 protein; another one is to trigger the assembly of NLRP3 inflammasome and lead to its stimulus such as production of ROS. Following triggered, active NLRP3 inflammasome recruits precursor caspase- 1 and cleaves it into active caspase-1, and then the cleaved caspase- 1 processes IL- $1 \beta$ and IL-18 precursors into mature IL- $1 \beta$ and IL-18, eventually augmenting the inflammatory responses and impairments [60, 61].

Recently, several studies have demonstrated that NLRP3 inflammasome pathway was activated after ICH 


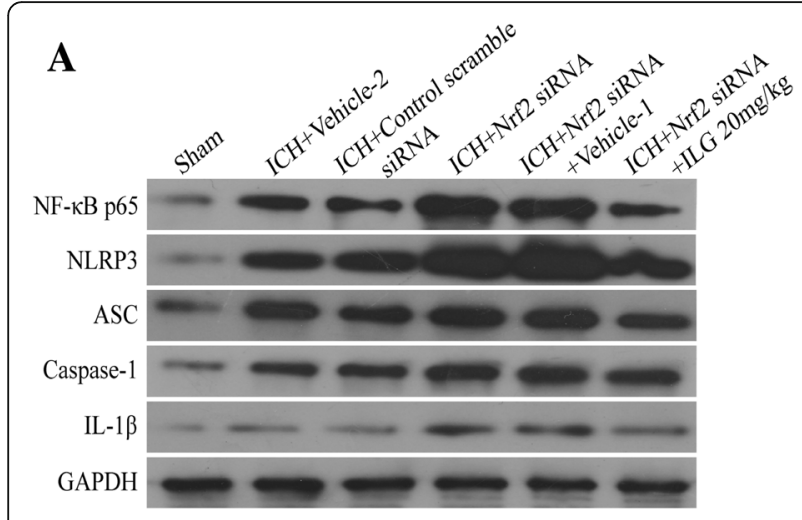

B

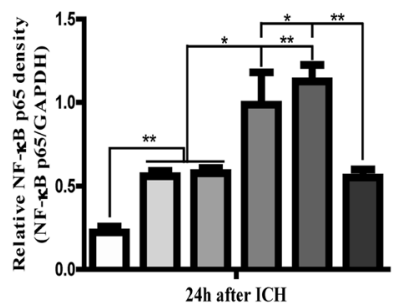

C

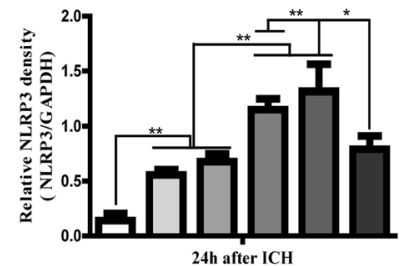

D

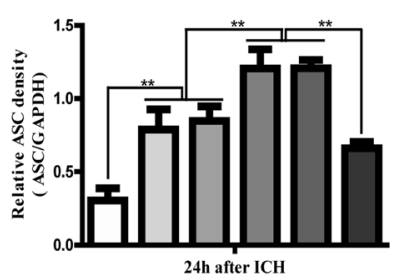

E

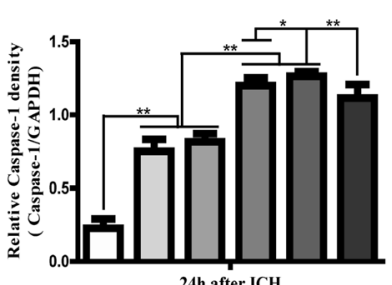

F

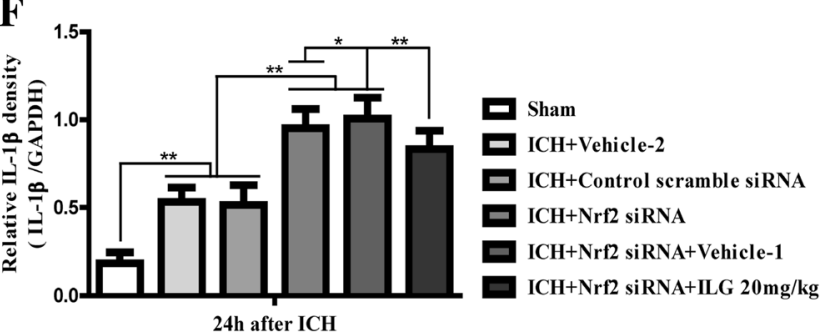

Fig. 10 Effects of Nrf2 siRNA and Nrf2 siRNA with ILG co-treatment on the protein levels of NF-kB p65 and NLRP3 inflammasome pathway components after ICH. WB assay (a) and quantification of NF-KB p65 (b), NLRP3 (c), ASC (d), caspase-1 (e), and IL-1 $\beta$ (f) protein levels after Nrf2 siRNA and ILG $20 \mathrm{mg} / \mathrm{kg}$ co-treatment at $24 \mathrm{~h}$ following ICH ( $n=6$ rats/group). Data are indicated by means \pm SD. ${ }^{* *} p<0.01 ;{ }^{*} p<0.05$

induction, and the inhibiting of NLRP3 using siRNA or recombinant adenovirus encoding NLRP3 RNAi could attenuate the brain injury including improving behavioral deficits and reducing brain edema and MPO level. Hence, ROS and the activation of NF- $\mathrm{kB}$ pathway were the crucial upstream signals, and blocking them can reduce the activation of NLRP3 inflammasome. In our study, we have verified that Nrf2 triggering via ILG administration significantly decreased the production of oxidative stress markers 3-NT and 8-OHdG and suppressed the activation of NF- $\mathrm{kB}$; meanwhile, the NLRP3 inflammasome was restrained. The results suggested that Nrf2 could downregulate the activity and expression of NLRP3 inflammasome (components) and were in keeping with previous reports $[18,22]$. To further proved our assumption, we conducted Nrf2 siRNA interfering and Nrf2 siRNA + ILG $20 \mathrm{mg} / \mathrm{kg}$ co-administration study in a rat $\mathrm{ICH}$ model. The results showed that after Nrf2 siRNA treatment, the brain injuries were more severe and ILG (20 mg/kg) obviously attenuated the impairments. These also were consistent with the studies of other groups, namely, Nrf2 was involved in the regulation of ILG-mediated NLRP3 inflammasome activation $[18,22]$ and the activation of Nrf2 pathway was neuroprotective $[9,12,13,31]$.

Microglia are the key immune cells existing in the central nervous system (CNS) and are commonly referred to as the macrophage of the brain. Microglia are considered to be the first non-neuronal cells to react to various pathological processes after $\mathrm{ICH}$ and thus once the condition ictus, microglia are immediately activated by a various of blood components and then activated microglia release multiple cytokines and chemokines, following peripheral inflammatory cells (including neutrophils, macrophages) infiltrating into the hemorrhagic brain and are activated, next producing a mass of cytokines, chemokines, and cytotoxicity substance $[4,62]$. Thus, both the activation and infiltration of neutrophils and microglia/macrophages synergistically contribute to the inflammatory brain injury post $\mathrm{ICH}$ and play crucial role on the pathological mechanisms $[4,62]$. Our experimental results have shown that ILG administration could notably reduce the number of perihematomal neutrophils and microglia/macrophages as well.

Also, iron, one key component of hemoglobin $(\mathrm{Hb})$ metabolites, was reported to be involved in the secondary brain injury. Excessive production of iron could lead to oxidative brain impairments by Fenton reaction, which yields massive ROS. Furthermore, HO-1 promotes the level of iron by participating in the degradation of heme $[63,64]$. Besides, ILG was also reported to counteract iron-catalyzed oxidative stress damages in HepG2 cells by AMPK-mediated GSK3 $\beta$ inhibition which was involved in mitochondrial dysfunction and superoxide generation [65]. Meanwhile, in our experiments, we 
found that ILG administration could significantly inhibit the level of ROS and promote the expression of HO-1 in the injury brain tissue. Thus, the relationship of iron metabolism and neuroprotective effects of ILG needs to be further explored.

Thrombin, a serine protease produced immediately in brain after $\mathrm{ICH}$ to prevent the bleeding. It may be a central injury mechanism of $\mathrm{ICH}$ and was shown to mediate the secondary brain injury by multiple pathways including complement cascade and proteaseactivated receptors (PAR) [63, 64]. Recently, thrombin was also reported to be involved in the activation of NLRP3 inflammasome and microglia and induced severe brain injury including brain edema, BBB disruption, and brain cell loss [66, 67]. In our study, we found that ILG $20 \mathrm{mg} / \mathrm{kg}$ could efficaciously blockade the activation of NLRP3 inflammasome and infiltration of neutrophils and microglia/macrophages into the injury brain tissue. Thus, whether ILG exerts its protective effects involved in the thrombin-mediated brain injury pathway remains to be further investigated.

There are several potential limitations deserving attention in our experiments. Firstly, ILG was reported to perform a variety of biological functions by regulating multiple signaling pathways, and we mainly concentrated on the Nrf2, ROS, NF- $\mathrm{KB}$, and NLRP3 inflammasome pathways. However, ILG may exert its effects on other signaling pathways. Secondly, we just carried out our study on a kind of ICH model (sterile-filtered collagenase type IV-induced), not concurrently on other ICH models such as autologous blood-imitated model of ICH. The results derived from our experiments should be more convincing by more than one model to be verified. Finally, collagenase itself is a kind of foreign matter and is unavoidable to trigger extra inflammatory responses. Consequently, further experiments are needed to settle these issues.

\section{Conclusions}

Taken together, our experiments have identified that ILG administration notably attenuated the early brain injury after $\mathrm{ICH}$ induction and the underlying molecular mechanisms of these beneficial effects are involved in the regulation of ROS and/or NF- $\mathrm{kB}$ on the activation of NLRP3 inflammasome pathway by the triggering of Nrf2 activity and Nrf2-induced antioxidant system. In addition, our experimental results might provide a novel therapeutical strategy for $\mathrm{ICH}$.

\section{Additional files}

Additional file 1: Experimental design and groups (a-c). MRI and Hematoma Volume Evaluation (d). The captions of Additional file 2 and 3 (e). (PDF $235 \mathrm{~kb}$ )
Additional file 2: Effects of ILG on the hematoma volume and expansion at $24 \mathrm{~h}$ and $72 \mathrm{~h}$ after ICH $(\mathrm{a}, \mathrm{b})$ and effects of ILG on the number of $\mathrm{CD} 68^{+}, \mathrm{Iba}-1^{+}$cells in the perihematomal brain tissue at $24 \mathrm{~h}$ after ICH (c-e). Representative MRI T2WI images (a) and quantitative analyses of hematoma volume (b) ( $n=6$ rats / group). Representative microscopic images (c) and quantitative analyses of $\mathrm{CD} 68^{+}, \mathrm{Iba}-1^{+}$cells $(\mathrm{d}, \mathrm{e})(n=6$ rats /group). Scale bar $=20 \mu \mathrm{m}$. Values are reported as means \pm SD. ${ }^{* *} p<0.01$, * $p<0.05$. (TIF $7318 \mathrm{~kb}$ )

Additional file 3: Mechanism diagram. Underlying molecular mechanisms of ILG's neuroprotective effects on the early brain injury after ICH induction. ILG alleviated the early brain injury following ICH may be involved in the regulation of ROS and / or NF-KB on the activation of NLRP3 inflammasome pathway by the triggering of Nrf2 activity and the induction of Nrf2-mediated antioxidant system. (TIF $232 \mathrm{~kb}$ )

\section{Abbreviations}

3-NT: 3-Nitrotyrosine; 6-OHDA: 6-Hydroxydopamine; 8-OHdG: 8Hydroxyguanosine; ANOVA: Analysis of variance; ARE: Antioxidant response element; BBB: Blood-brain barrier; BSA: Bovine serum albumin; BWC: Brain water content; CAT: Catalase; CNS: Central nervous system; DAB: 3,3Diaminobenzidine; DAPI: 4'6-Diamidino-2-phenylindole;

DMSO: Dimethylsulfoxide; EB: Evans blue; EC: Energy charge; EDTA: Ethylene diamine tetraacetic acid; ELISA: Enzyme-linked immunosorbent assay; ERK1/ 2: Extracellular signal-regulated kinase1/2; FJC: Fluoro-Jade ${ }^{\circledast} \mathrm{C} ; \mathrm{G}$. uralensis: Glycyrrhiza uralensis; GAPDH: Glyceraldehyde 3-phosphate dehydrogenase; GPX: Glutathione peroxidase; GSH/GSSG: Glutathione/oxidized glutathione; GST: Glutathione-S-transferase; H\&E: Hematoxylin and eosin; Hb: Hemoglobin; HO-1: Heme oxygenase-1; HRP: Horseradish peroxidase; i.p.: Intraperitoneal injection; ICH: Intracerebral hemorrhage;

IF: Immunofluorescence; IHC: Immunohistochemistry; IL-1 $\beta$ : Interleukin-1 beta; ILG: Isoliquiritigenin; IKBa: Inhibitor of KBa; Keap1: Kelchlike ECHassociated protein 1; LPS: Lipopolysaccharide; LSD: Least significant difference; mNSS: Modified Neurological Severity Score;

MPO: Myeloperoxidase; MRI: Magnetic resonance imaging; NF-KB: Nuclear factor-KB; NLRP3: Nod-like receptor family, pyrin domain-containing 3; NO: Nitric oxide; NQO1: NAD(P)H: quinone oxidoreductase-1; Nrf2: Nuclear factor erythroid-2 related factor 2; PAR: Protease-activated receptor; PBS: Phosphate buffer solution; PRR: Pattern recognition receptor; ROS: Reactive oxygen species; RT-qPCR: Real-time reverse transcriptionquantitative polymerase chain reaction; SD: Standard deviation; SD rats: Sprague-Dawley rats; siRNA: Small interfering RNA; SNP: Sodium nitroprusside; SOD: Superoxide dismutase; SPF: Specific pathogen-free; T2WI: T2-weighted images; TAN: Total adenine nucleotides; WB: Western blot

\section{Acknowledgements}

It has been shown as Funding.

\section{Funding}

This work was supported by the National Natural Science Foundation of China (Nos. 81671125, 81271314, and 30500526), Special Project on the Integration of Industry, Education and Research of Guangdong Province and Ministry of Education (No. 2012B091100154), Natural Science Foundation of Guangdong (No. 2014A030313346 and 5300468), and the Guangdong Provincial Clinical Medical Centre for Neurosurgery (No. 2013B020400005).

\section{Availability of data and materials}

Please contact author for data requests.

\section{Authors' contributions}

YZC and JZ conceived and designed the experiments. JZ performed the experiments. $Y Z C$ and $J Z$ analyzed the data. JZ wrote the paper. YZC, RD, LF, SY, XQD, ZHF, ZCX, and SZZ contributed to the paper revision, provided experimental technical support, and assisted in completing the study at different stages. All authors read and approved the final manuscript.

\section{Competing interests}

The authors declare that they have no competing interests. 


\section{Ethics approval}

All experimental procedures and animal care were approved by the Southern Medical University Ethics Committee and were conducted in accordance with the guidelines of the National Institutes of Health on the care and use of animals.

\section{Publisher's Note}

Springer Nature remains neutral with regard to jurisdictional claims in published maps and institutional affiliations.

\section{Author details}

'Department of Neurosurgery, Zhujiang Hospital, The National Key Clinical Specialty, The Neurosurgery Institute of Guangdong Province, Guangdong Provincial Key Laboratory on Brain Function Repair and Regeneration, The Engineering Technology Research Center of Education Ministry of China, Southern Medical University, Guangzhou 510282, China. ${ }^{2}$ Department of Neurosurgery, Jingmen No. 1 People's Hospital, Jingmen 448000, Hubei, China. ${ }^{3}$ Department of Neurosurgery, Affiliated Hospital of Xiangnan University, Chenzhou 423000, Hunan, China. ${ }^{4}$ Department of Neurosurgery, The Fifth Affiliated Hospital of Southern Medical University, Guangzhou 510900, Guangdong, China. ${ }^{5}$ Department of Neurosurgery, Gaoqing Campus of Central Hospital of Zibo, Gaoging People's Hospital, Gaoging, Zibo 256300, Shandong, China. ${ }^{6}$ Department of Neurosurgery, 999 Brain Hospital, Jinan University, Guangzhou 510510, Guangdong, China.

Received: 14 February 2017 Accepted: 5 June 2017

\section{Published online: 13 June 2017}

\section{References}

1. Keep RF, Hua Y, Xi G. Intracerebral haemorrhage: mechanisms of injury and therapeutic targets. Lancet Neurol. 2012;11:720-31.

2. Adeoye O, Broderick JP. Advances in the management of intracerebral hemorrhage. Nat Rev Neurol. 2010;6:593-601.

3. Chen S, Yang Q, Chen G, Zhang JH. An update on inflammation in the acute phase of intracerebral hemorrhage. Transl Stroke Res. 2015;6:4-8.

4. Zhou Y, Wang Y, Wang J, Anne SR, Yang QW. Inflammation in intracerebral hemorrhage: from mechanisms to clinical translation. Prog Neurobiol. 2014; 115:25-44.

5. Hu X, Tao C, Gan Q, Zheng J, Li H, You C. Oxidative stress in intracerebral hemorrhage: sources, mechanisms, and therapeutic targets. Oxid Med Cell Longev. 2016;2016:3215391.

6. Broderick JP, Brott TG, Duldner JE, Tomsick T, Huster G. Volume of intracerebral hemorrhage. A powerful and easy-to-use predictor of 30-day mortality. Stroke. 1993;24:987-93.

7. Duan X, Wen Z, Shen H, Shen M, Chen G. Intracerebral hemorrhage, oxidative stress, and antioxidant therapy. Oxid Med Cell Longev. 2016;2016: 1203285.

8. Ma Q, Chen S, Hu Q, Feng H, Zhang JH, Tang J. NLRP3 inflammasome contributes to inflammation after intracerebral hemorrhage. Ann Neurol. 2014;75:209-19

9. Denzer I, Munch G, Friedland K. Modulation of mitochondrial dysfunction in neurodegenerative diseases via activation of nuclear factor erythroid-2-related factor 2 by food-derived compounds. Pharmacol Res. 2016;103:80-94.

10. Calkins MJ, Johnson DA, Townsend JA, Vargas MR, Dowell JA, Williamson TP, Kraft AD, Lee JM, Li J, Johnson JA. The Nrf2/ARE pathway as a potential therapeutic target in neurodegenerative disease. Antioxid Redox Signal. 2009;11:497-508.

11. Shang H, Yang D, Zhang W, Li T, Ren X, Wang X, Zhao W. Time course of Keap1-Nrf2 pathway expression after experimental intracerebral haemorrhage: correlation with brain oedema and neurological deficit. Free Radic Res. 2013;47:368-75.

12. Iniaghe LO, Krafft PR, Klebe DW, Omogbai EK, Zhang JH, Tang J. Dimethyl fumarate confers neuroprotection by casein kinase 2 phosphorylation of Nrf2 in murine intracerebral hemorrhage. Neurobiol Dis. 2015;82:349-58.

13. Zhao X, Sun G, Zhang J, Ting SM, Gonzales N, Aronowski J. Dimethyl fumarate protects brain from damage produced by intracerebral hemorrhage by mechanism involving Nrf2. Stroke. 2015;46:1923-8.

14. Wang J, Fields J, Zhao C, Langer J, Thimmulappa RK, Kensler TW, Yamamoto M, Biswal S, Dore S. Role of Nrf2 in protection against intracerebral hemorrhage injury in mice. Free Radic Biol Med. 2007;43:408-14.
15. Zhao X, Sun G, Zhang J, Strong R, Dash PK, Kan YW, Grotta JC, Aronowski J. Transcription factor Nrf2 protects the brain from damage produced by intracerebral hemorrhage. Stroke. 2007;38:3280-6.

16. Yuan B, Shen H, Lin L, Su T, Zhong S, Yang Z. Recombinant adenovirus encoding NLRP3 RNAi attenuate inflammation and brain injury after intracerebral hemorrhage. J Neuroimmunol. 2015;287:71-5.

17. Feng $L$, Chen Y, Ding R, Fu Z, Yang S, Deng X, Zeng J. P2X7R blockade prevents NLRP3 inflammasome activation and brain injury in a rat model of intracerebral hemorrhage: involvement of peroxynitrite. J Neuroinflammation. 2015;12:190.

18. Liu X, Zhang X, Ding Y, Zhou W, Tao L, Hu R. Nuclear factor E2-related factor-2 (Nrf2) negatively regulates NLRP3 inflammasome activity by inhibiting reactive oxygen species (ROS)-induced NLRP3 priming. Antioxid Redox Signal. 2017;26(1):28-43.

19. Rzepecka J, Pineda MA, Al-Riyami L, Rodgers DT, Huggan JK, Lumb FE, Khalaf Al, Meakin PJ, Corbet M, Ashford ML, et al. Prophylactic and therapeutic treatment with a synthetic analogue of a parasitic worm product prevents experimental arthritis and inhibits IL-1 beta production via NRF2-mediated counter-regulation of the inflammasome. J Autoimmun. 2015;60:59-73.

20. Peng F, Du Q, Peng C, Wang N, Tang H, Xie X, Shen J, Chen J. A review: the pharmacology of isoliquiritigenin. Phytother Res. 2015;29:969-77.

21. Gnanaguru G, Choi AR, Amarnani D, D'Amore PA. Oxidized lipoprotein uptake through the CD36 receptor activates the NLRP3 inflammasome in human retinal pigment epithelial cells. Invest Ophthalmol Vis Sci. 2016;57:4704-12.

22. Honda H, Nagai $Y$, Matsunaga T, Okamoto N, Watanabe $Y$, Tsuneyama K, Hayashi H, Fujii I, Ikutani M, Hirai $Y$, et al. Isoliquiritigenin is a potent inhibitor of NLRP3 inflammasome activation and diet-induced adipose tissue inflammation. J Leukoc Biol. 2014;96:1087-100.

23. Liu S, Zhu L, Zhang J, Yu J, Cheng X, Peng B. Anti-osteoclastogenic activity of isoliquiritigenin via inhibition of NF-kappaB-dependent autophagic pathway. Biochem Pharmacol. 2016;106:82-93.

24. Kwon HM, Choi YJ, Choi JS, Kang SW, Bae JY, Kang IJ, Jun JG, Lee SS, Lim SS, Kang YH. Blockade of cytokine-induced endothelial cell adhesion molecule expression by licorice isoliquiritigenin through NF-kappaB signal disruption. Exp Biol Med (Maywood). 2007;232:235-45.

25. Wu Y, Chen X, Ge X, Xia H, Wang Y, Su S, Li W, Yang T, Wei M, Zhang H, et al. Isoliquiritigenin prevents the progression of psoriasis-like symptoms by inhibiting NF-kappaB and proinflammatory cytokines. J Mol Med (Berl). 2016;94:195-206.

26. Denzer I, Munch G, Pischetsrieder M, Friedland K. S-allyl-L-cysteine and isoliquiritigenin improve mitochondrial function in cellular models of oxidative and nitrosative stress. Food Chem. 2016;194:843-8.

27. Foresti R, Bains SK, Pitchumony TS, de Castro BL, Drago F, Dubois-Rande $J$, Bucolo C, Motterlini R. Small molecule activators of the Nrf2-HO-1 antioxidant axis modulate heme metabolism and inflammation in BV2 microglia cells. Pharmacol Res. 2013;76:132-48.

28. Gong H, Zhang BK, Yan M, Fang PF, Li HD, Hu CP, Yang Y, Cao P, Jiang P, Fan XR. A protective mechanism of licorice (Glycyrrhiza uralensis): isoliquiritigenin stimulates detoxification system via Nrf2 activation. J Ethnopharmacol. 2015;162:134-9.

29. Park SM, Lee JR, Ku SK, Cho IJ, Byun SH, Kim SC, Park SJ, Kim YW. Isoliquiritigenin in licorice functions as a hepatic protectant by induction of antioxidant genes through extracellular signal-regulated kinase-mediated NF-E2-related factor-2 signaling pathway. Eur J Nutr. 2016;55(8):2431-44.

30. Rosenberg GA, Mun-Bryce S, Wesley M, Kornfeld M. Collagenase-induced intracerebral hemorrhage in rats. Stroke. 1990;21:801-7.

31. Xue F, Huang JW, Ding PY, Zang HG, Kou ZJ, Li T, Fan J, Peng ZW, Yan WJ. $\mathrm{Nrf2/antioxidant} \mathrm{defense} \mathrm{pathway} \mathrm{is} \mathrm{involved} \mathrm{in} \mathrm{the} \mathrm{neuroprotective} \mathrm{effects}$ of Sirt1 against focal cerebral ischemia in rats after hyperbaric oxygen preconditioning. Behav Brain Res. 2016;309:1-8.

32. Dang B, Li H, Xu X, Shen H, Wang Y, Gao A, He W, Wang Z, Chen G. Cyclophilin Avcluster of differentiation 147 interactions participate in early brain injury after subarachnoid hemorrhage in rats. Crit Care Med. 2015;43:e369-81.

33. Chen J, Li Y, Wang L, Zhang Z, Lu D, Lu M, Chopp M. Therapeutic benefit of intravenous administration of bone marrow stromal cells after cerebral ischemia in rats. Stroke. 2001;32:1005-11.

34. Chen J, Sanberg PR, Li Y, Wang L, Lu M, Willing AE, Sanchez-Ramos J, Chopp M. Intravenous administration of human umbilical cord blood reduces behavioral deficits after stroke in rats. Stroke. 2001;32:2682-8.

35. Ding R, Feng L, He L, Chen Y, Wen P, Fu Z, Lin C, Yang S, Deng X, Zeng J, Sun $G$. Peroxynitrite decomposition catalyst prevents matrix metalloproteinase- 9 activation and neurovascular injury after hemoglobin injection into the caudate nucleus of rats. Neuroscience. 2015;297:182-93. 
36. Ding $R$, Chen $Y$, Yang S, Deng X, Fu Z, Feng L, Cai Y, Du M, Zhou Y, Tang Y. Blood-brain barrier disruption induced by hemoglobin in vivo: Involvement of up-regulation of nitric oxide synthase and peroxynitrite formation. Brain Res. 2014;1571:25-38.

37. Yang F, Wang Z, Zhang JH, Tang J, Liu X, Tan L, Huang QY, Feng H. Receptor for advanced glycation end-product antagonist reduces blood-brain barrier damage after intracerebral hemorrhage. Stroke. 2015;46:1328-36.

38. Belayev L, Busto R, Zhao W, Ginsberg MD. Quantitative evaluation of bloodbrain barrier permeability following middle cerebral artery occlusion in rats. Brain Res. 1996;739:88-96.

39. Uyama O, Okamura N, Yanase M, Narita M, Kawabata K, Sugita M. Quantitative evaluation of vascular permeability in the gerbil brain after transient ischemia using Evans blue fluorescence. J Cereb Blood Flow Metab. 1988;8:282-4.

40. Yang S, Chen Y, Deng X, Jiang W, Li B, Fu Z, Du M, Ding R. Hemoglobininduced nitric oxide synthase overexpression and nitric oxide production contribute to blood-brain barrier disruption in the rat. J Mol Neurosci. 2013; 51:352-63.

41. Schmued LC, Stowers CC, Scallet AC, Xu L. Fluoro-Jade C results in ultra high resolution and contrast labeling of degenerating neurons. Brain Res. 2005:1035:24-31.

42. Min H, Jang YH, Cho IH, Yu SW, Lee SJ. Alternatively activated braininfiltrating macrophages facilitate recovery from collagenase-induced intracerebral hemorrhage. Mol Brain. 2016;9:42.

43. Livak KJ, Schmittgen TD. Analysis of relative gene expression data using real-time quantitative PCR and the 2(-Delta Delta C(T)) Method. Methods. 2001;25:402-8

44. Mracsko E, Veltkamp R. Neuroinflammation after intracerebral hemorrhage. Front Cell Neurosci. 2014;8:388.

45. Qu J, Chen W, Hu R, Feng $H$. The injury and therapy of reactive oxygen species in intracerebral hemorrhage looking at mitochondria. Oxid Med Cell Longev. 2016;2016:2592935.

46. Ziai WC. Hematology and inflammatory signaling of intracerebral hemorrhage. Stroke. 2013:44:S74-8.

47. Jang EY, Choe ES, Hwang M, Kim SC, Lee JR, Kim SG, Jeon JP, Buono RJ, Yang $\mathrm{CH}$. Isoliquiritigenin suppresses cocaine-induced extracellular dopamine release in rat brain through GABA(B) receptor. Eur J Pharmacol. 2008;587:124-8.

48. Jeon JP, Buono RJ, Han BG, Jang EY, Kim SC, Yang CH, Hwang M. Proteomic and behavioral analysis of response to isoliquiritigenin in brains of acute cocaine treated rats. J Proteome Res. 2008;7:5094-102.

49. Lee MJ, Yang $\mathrm{CH}$, Jeon JP, Hwang M. Protective effects of isoliquiritigenin against methamphetamine-induced neurotoxicity in mice. J Pharmacol Sci. 2009;111:216-20.

50. Zhan C, Yang J. Protective effects of isoliquiritigenin in transient middle cerebral artery occlusion-induced focal cerebral ischemia in rats. Pharmacol Res. 2006;53:303-9.

51. Hwang CK, Chun HS. Isoliquiritigenin isolated from licorice Glycyrrhiza uralensis prevents 6-hydroxydopamine-induced apoptosis in dopaminergic neurons. Biosci Biotechnol Biochem. 2012;76:536-43.

52. Yang EJ, Min JS, Ku HY, Choi HS, Park MK, Kim MK, Song KS, Lee DS. Isoliquiritigenin isolated from Glycyrrhiza uralensis protects neuronal cells against glutamate-induced mitochondrial dysfunction. Biochem Biophys Res Commun. 2012:421:658-64.

53. Mogami S, Sadakane C, Nahata M, Mizuhara Y, Yamada C, Hattori T, Takeda $H$. CRF receptor 1 antagonism and brain distribution of active components contribute to the ameliorative effect of rikkunshito on stress-induced anorexia. Sci Rep. 2016;6:27516.

54. Luo Y, Eggler AL, Liu D, Liu G, Mesecar AD, van Breemen RB. Sites of alkylation of human Keap1 by natural chemoprevention agents. J Am Soc Mass Spectrom. 2007;18:2226-32.

55. Lee SH, Kim JY, Seo GS, Kim YC, Sohn DH. Isoliquiritigenin, from Dalbergia odorifera, up-regulates anti-inflammatory heme oxygenase-1 expression in RAW264.7 macrophages. Inflamm Res. 2009;58:257-62.

56. Wang $R$, Zhang CY, Bai LP, Pan HD, Shu LM, Kong AN, Leung EL, Liu L, Li T. Flavonoids derived from liquorice suppress murine macrophage activation by up-regulating heme oxygenase- 1 independent of Nrf2 activation. Int Immunopharmacol. 2015;28:917-24

57. Honda H, Nagai Y, Matsunaga T, Saitoh S, Akashi-Takamura S, Hayashi H, Fujii I, Miyake K, Muraguchi A, Takatsu K. Glycyrrhizin and isoliquiritigenin suppress the LPS sensor toll-like receptor 4/MD-2 complex signaling in a different manner. J Leukoc Biol. 2012;91:967-76.
58. Zhu L, Wei H, Wu Y, Yang S, Xiao L, Zhang J, Peng B. Licorice isoliquiritigenin suppresses RANKL-induced osteoclastogenesis in vitro and prevents inflammatory bone loss in vivo. Int J Biochem Cell Biol. 2012;44:1139-52.

59. Watanabe $Y$, Nagai $Y$, Honda $H$, Okamoto $N$, Yamamoto $S$, Hamashima $T$, Ishii $Y$, Tanaka M, Suganami T, Sasahara M, et al. Isoliquiritigenin attenuates adipose tissue inflammation in vitro and adipose tissue fibrosis through inhibition of innate immune responses in mice. Sci Rep. 2016;6:23097.

60. Sharma D, Kanneganti TD. The cell biology of inflammasomes: mechanisms of inflammasome activation and regulation. J Cell Biol. 2016;213:617-29.

61. Lamkanfi M, Dixit VM. Mechanisms and functions of inflammasomes. Cell. 2014:157:1013-22

62. Zhang Z, Zhang Z, Lu H, Yang Q, Wu H, Wang J. Microglial polarization and inflammatory mediators after intracerebral hemorrhage. Mol Neurobiol. 2017;54:1874-86.

63. Babu R, Bagley JH, Di C, Friedman AH, Adamson C. Thrombin and hemin as central factors in the mechanisms of intracerebral hemorrhage-induced secondary brain injury and as potential targets for intervention. Neurosurg Focus. 2012;32:E8.

64. Hua Y, Keep RF, Hoff JT, Xi G. Brain injury after intracerebral hemorrhage: the role of thrombin and iron. Stroke. 2007:38:759-62.

65. Choi SH, Kim YW, Kim SG. AMPK-mediated GSK3beta inhibition by isoliquiritigenin contributes to protecting mitochondria against ironcatalyzed oxidative stress. Biochem Pharmacol. 2010;79:1352-62.

66. Wan S, Cheng Y, Jin H, Guo D, Hua Y, Keep RF, Xi G. Microglia activation and polarization after intracerebral hemorrhage in mice: the role of protease-activated receptor-1. Transl Stroke Res. 2016;7(6):478-87.

67. Zuo D, Ye X, Yu L, Zhang L, Tang J, Cui C, Bao L, Zan K, Zhang Z, Yang X, et al. ROS/TXNIP pathway contributes to thrombin induced NLRP3 inflammasome activation and cell apoptosis in BV2 cells. Biochem Biophys Res Commun. 2017;485(2):499-505.

\section{Submit your next manuscript to BioMed Central and we will help you at every step:}

- We accept pre-submission inquiries

- Our selector tool helps you to find the most relevant journal

- We provide round the clock customer support

- Convenient online submission

- Thorough peer review

- Inclusion in PubMed and all major indexing services

- Maximum visibility for your research

Submit your manuscript at www.biomedcentral.com/submit
) Biomed Central 